\title{
Chinese Entrepreneurs, Social Networks, and Guanxi
}

\section{Ronald S. Burt ${ }^{1}$ and Katarzyna Burzynska ${ }^{2}$ \\ ${ }^{1}$ University of Chicago, USA, and ${ }^{2}$ Radboud University Nijmegen, Netherlands}

ABSTRACT Intending to clear space for rigorous integrative research bridging theory and research across East and West, we highlight four conclusions from exceptional data on the networks around Chinese entrepreneurs: (1) The broker networks associated with business success in the West are also associated with success in China; (2) The trust correlates of closed networks in the West are similarly correlated in China; (3) History and trust proven in events emerge as especially important to the Chinese entrepreneurs; (4) High-quality network data on Chinese business leaders are a practical reality. We use the results to define a network perspective on guanxi ties that can be common ground for integrating results across East and West, and guide future research on the role networks play in Chinese business.

KEYWORDS entrepreneurship, guanxi, social networks

\section{INTRODUGTION}

Two principles in network theory, often discussed as principles of brokerage and closure, are that achievement is more likely from people with large, open networks and that trust and reputation are more likely in closed networks. We discuss evidence for each principle below, but our introductory point is that the extensive evidence on the two principles from studies of business in North America and Europe warrants attention when thinking about China, where a critical role is advocated for social networks in the rise of entrepreneurial business and China's emergence as a global economic power (Nee \& Opper, 2012). Our purpose in this paper is to present unprecedented evidence of the two network principles operating in the networks around Chinese entrepreneurs. Much of what we report supports the thesis in Nee and Opper (2012) that China's emergence was a 'bottom up' process. In the absence of institutional support, Chinese entrepreneurs constructed in their social networks personal institutions to support their businesses. More, our results are relevant to generalizations about the role social networks play in Chinese business, some arguing that Chinese networks, often discussed as guanxi,

Corresponding author: Ronald S. Burt (ron.burt@chicagobooth.edu) 
are fundamentally different from networks in the West. Our results support the claim in certain ways, but also show that much of trust and achievement in China has the same network correlations associated with trust and achievement in the West.

The paper is in four parts. We introduce the network data, then turn to construct validity. Our network data have construct validity to the extent that network measures computed from the data have correlates established in theory and prior research. We report on two of the most basic correlates: success and trust. Construct validity is twice valuable here. First, it establishes that the Chinese data measure what they purport to measure. Second, and more to our purpose in this paper, it highlights similarities and differences in the way that basic network mechanisms operate in China versus the West. We close with four conclusions and suggestive beginnings for future research.

\section{SOGIAL NETWORKS AND GHINESE ENTREPRENEURS}

Collecting network data from a large random sample of entrepreneurs drawn from a heterogeneous area population is a challenge - all the more so in the context of China's economy where entrepreneurs are keen to protect the identity of their personal and professional contacts. Information on personal networks and appreciated business contacts is understood in China to be a key determinant of success. Information shared on even the identity of key suppliers or customers requires a certain level of trust.

Fortunately, much was learned from the research strategy used to initially gather network data on a national probability sample of Americans for the 1984 General Social Survey (Burt, 1984; Marsden, 1987). The strategy is to ask the survey respondent for the names of people with whom he or she has particularly strong relations, then ask about the nature of relationships with and among the cited contacts. The former kinds of questions are 'name generators', the latter 'name interpreters'. Name generators and interpreters have become routine in network survey research (Marsden, 2011), in network surveys of management populations in particular (Burt, 2010: 281ff.), and have precedent in China (Batjargal, 2007a; Batjargal, Hitt, Tsui, Arregle, Webb, \& Miller 2013; Bian \& Li, 2012; Ruan, 1998; Xiao \& Tsui, 2007; the 2003 Chinese General Social Survey). This paper is the first report on the strategy used with a large random sample of Chinese entrepreneurs in diverse areas, building their businesses in the shadow of a suspicious government.

Name generators and interpreters were adapted from management research to extend the usual research design into the history of the networks around a large area probability sample of Chinese entrepreneurs. The exceptional data we have on the Chinese networks is foundational to the substantive significance of the results we present, but research design is of less general interest than our substantive results, so we put the design discussion in an appendix for readers interested in replicating the results to be reported. Suffice it here to say that we have data on 


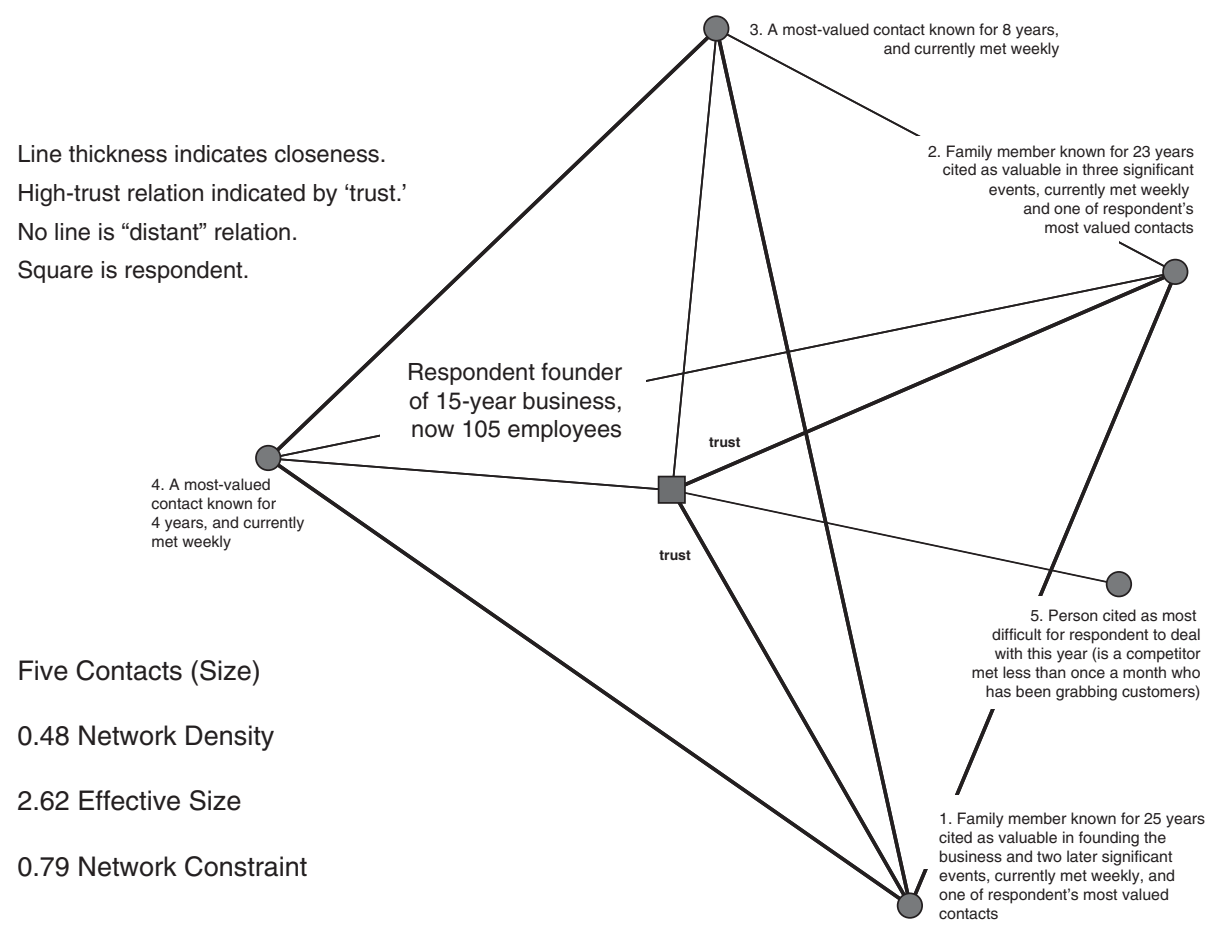

Figure 1. A network smaller and more dense than average

the social networks of around 700 Chinese entrepreneurs whose businesses are a stratified random sample of private enterprises in three provinces surrounding the Yangtze River Delta: China's financial center, Shanghai, with Nanjing the capital of Jiangsu Province to the north, and Hangzhou the capital of Zhejiang Province to the south. The three provinces account in 2013 for $20.2 \%$ of China's gross domestic product, and 31.9\% of China's imports and exports. ${ }^{[1]}$ The sampled entrepreneurs are a 2012 continuation of the samples surveyed in 2006 and 2009 by Nee and Opper (2012).

Two example networks from the data are displayed in Figures 1 and 2. The displays provide a quick introduction to the data, and will be helpful in later discussion. Name generator items elicited the names of key contacts and name interpreter items elicited information on the nature and strength of relations with and among the cited contacts. Networks are visualized in the figures using a spring-embedding algorithm that locates people close together as a function of their connection with each other and through others (Borgatti, 2002). A square dot indicates the survey respondent. Line thickness indicates emotional closeness. The absence of a line indicates a 'distant' relationship. Frequently used metrics summarizing network structure are displayed to the left in each figure.

Figure 1 displays one of the smaller, less open networks in the data. The business was founded 15 years ago by the survey respondent, and has grown to employ 105 


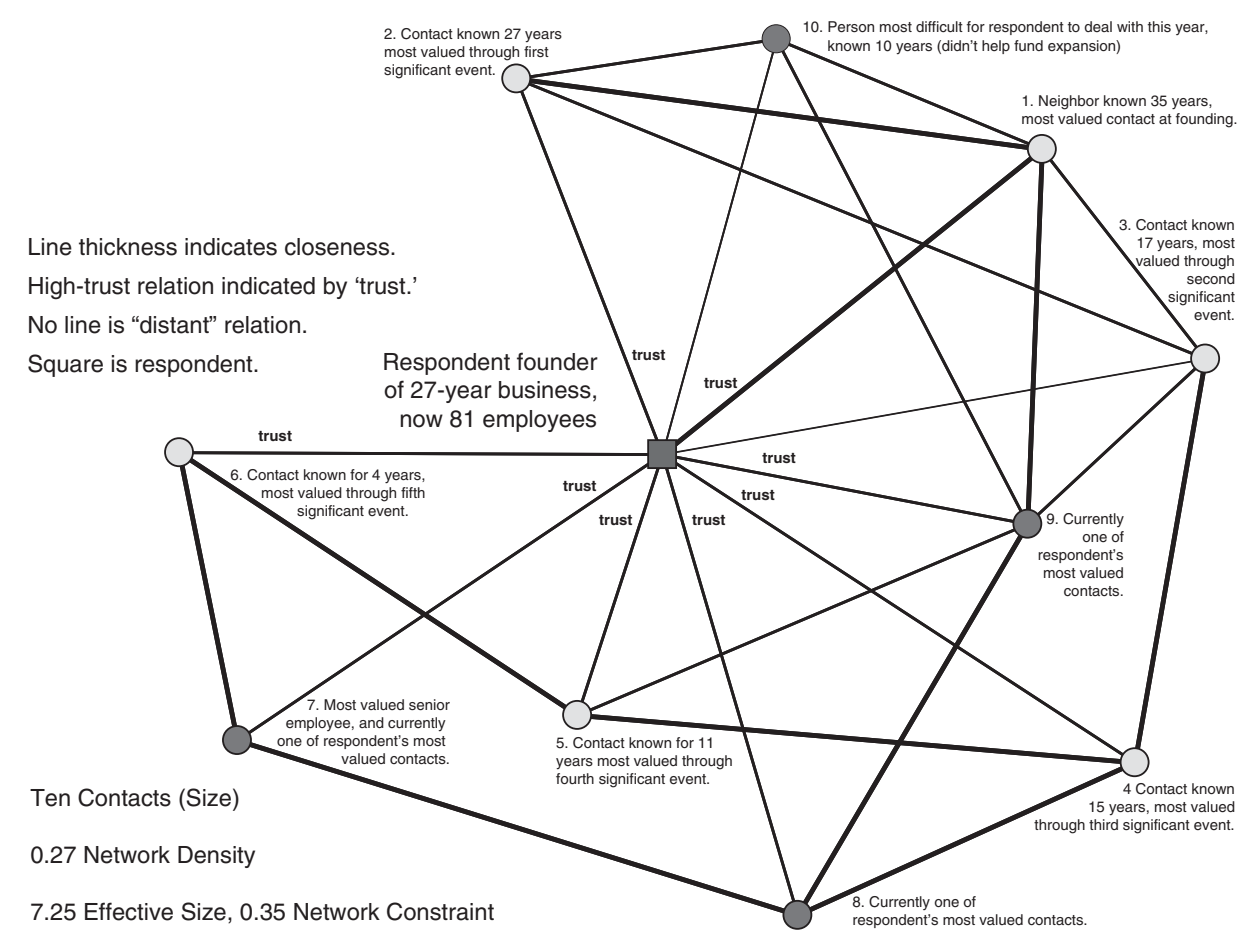

Figure 2. A network larger and less dense than average

people. The respondent cites five key contacts, four of whom are interconnected as a core to the network, two of whom are members of the respondent's family. The two family contacts have been known for over 20 years, and are the only contacts in whom the entrepreneur has high trust. The respondent feels distant from the person who has been his greatest source of difficulty this year, and feels that the other members of his core network share his distance from the difficult person.

At the other end of the data distribution, Figure 2 displays one of the larger, more open networks. There are 10 key contacts, none of whom are family (versus five contacts in Figure 1, two of whom are family), and the average strength of connections between contacts is 0.27 on a scale of zero to one (versus 0.55 density in Figure 1). The respondent generating the network in Figure 2 founded the business 27 years ago, and has grown the business to 81 employees.

The larger, more open network in Figure 2 implies that the entrepreneur in Figure 2 operates in a way different from the entrepreneur in Figure 1, but there is a feature to the network data that makes the difference more obvious: the data extend back into the history of a business. Contacts in Figure 1 are all the same color because they were all named on standard name generators that elicit the current network around a business leader. Contacts in Figure 2 are in two colors. The dark dots are contacts cited on the standard name generators as current 
contacts. The gold dots are contacts cited only as valuable during significant events in the history of the business.

Given a time line from the year of the survey, 2012, back to the year in which the business was founded, each respondent was asked to identify up to five significant events for the business, the year in which the event happened, and a person who was most valued during the event (see Figure A2 in the Appendix). Everyone was asked for the contact most valued in founding the business, then the contacts most valued in dealing with subsequent significant events. Almost all of the entrepreneurs identified five significant events after the business was founded (675 five, 13 four, 12 three). We discuss as 'event' contacts the people named as most valued during the founding or the subsequent events.

Event contacts reveal a profound difference in behavior by the entrepreneurs. The entrepreneur in Figure 1 turns to the same people again and again during significant events. Contact 1 (southeast in Figure 1) is a member of the entrepreneur's family who was most valued in founding the business, most valued during two later significant events, and he is one of the entrepreneur's most valued current contacts. Contact 2 (northeast in Figure 1) is another member of the entrepreneur's family who was the most valued contact during three other significant events in the history of the business, and he too is one of the entrepreneur's most valued current contacts. In short, the closed network in Figure 1 is a fortress anchored on the entrepreneur's family, within which the entrepreneur searches for needed support. In contrast, the entrepreneur in Figure 2 names a different person as most valued in each of the significant events in his firm's history, and none of his event contacts is currently a most-valued contact. The network changed over time, in response to significant events.

\section{NETWORK BROKERAGE AND BUSINESS SUCGESS}

Network theory predicts that achievement is associated with large, open networks. The more disconnected a person's contacts, the more likely the contacts are in separate groups creating opportunities to broker information flow between groups. The separations between groups are holes in the surrounding social structure, or more simply 'structural holes', and a person whose network spans the holes, a 'network broker', has information advantages of breadth, timing, and arbitrage such that the broker can more successfully move ideas and practice from groups, where the ideas and practice are familiar, to new groups where the ideas and practice would be new and valuable. Differences in understanding between groups make it difficult for information to move directly between groups. Brokers translate what is known here into what can be understood and seen as valuable over there. In a phrase, information is 'sticky' within groups, and network brokers are the mechanism that clears the sticky-information market. Network brokers are rewarded for their detection and development of good ideas with accolades, compensation, and elevation to leadership positions. Images of sticky information 

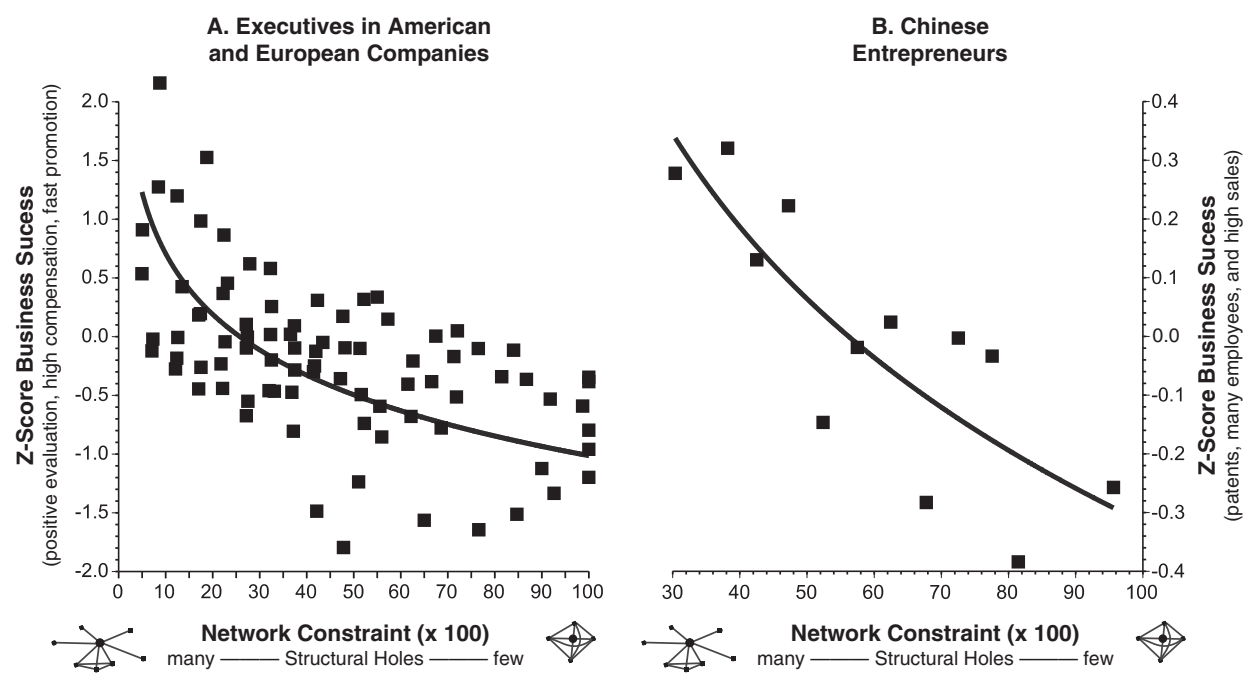

Figure 3. Network brokerage and business success

Notes: Dots are average scores for a five-point interval of network constraint in a study population. Lines are vertical axis predicted by the natural logarithm of network constraint. Statistics in the graphs are computed from the displayed data. Graph A shows success (measured by evaluation, compensation, or promotion) increasing with more structural holes in the networks around 1,989 analysts, bankers, and managers in American and European companies, with controls for differences between the individuals (from Burt, Kilduff, \& Tasselli, 2013: 535; Burt, 2010: 26; cf. Burt 2005: 56). Graph B shows business success increasing with more structural holes in networks around the 700 Chinese entrepreneurs running each business. Business success is measured by the first principal component of patents, employees, and sales adjusted for having a research and development department $(\mathbf{z}$-score $=[$ business success in Table $1-0.817 \mathrm{RD}+0.411] / 0.909)$.

within groups and network brokers between groups are rooted in the golden age of social psychology (Festinger, Schachter, \& Back, 1950; Leavitt, 1951), made precise in subsequent network theory (Burt, 1982, 1992; Cook, Emerson, Gillmore, \& Yamagishi, 1983; Freeman, 1977; Granovetter, 1973; Lin, 2001; Lin, Ensel, \& Vaughn, 1981). Argument and evidence are reviewed elsewhere (Burt, 2005; Burt, Kilduff, \& Tasselli, 2013), but reviews fall quickly out of date as this is a vibrant area of research that expands every year with significant contributions.

\section{Brokerage and Success in the West}

Figure 3A contains results on the success associated with networks in the West. The graph is illustrative evidence used in a recent review of network advantage (Burt, Kilduff, \& Tasselli, 2013: 535). The data describe success and networks for two thousand analysts, bankers, and managers in six large American or European companies. Success is measured on the vertical axis within each company by annual evaluations, compensation, or promotion expressed as a z-score adjusted for relevant background differences between senior employees. Positive scores indicate 
a person ahead of peers within his or her company. Zero indicates a person just keeping up with peers. Negative scores indicate a person fallen behind peers.

The horizontal axes in Figure 3 distinguish people by network constraint - the extent to which a person's network is closed, providing no access to structural holes. Intuitively, network constraint is the percent of person's network time and energy consumed by one group. Constraint decreases with the extent to which the person has many contacts (size), increases with the extent to which the person's network is closed by strong connections among contacts (density), and increases with the extent to which the person's network is closed by a partner strongly connected with all contacts (hierarchy). As discussed in the reviews cited above, network constraint is closely correlated with two other network metrics often used to measure access to structural holes - effective size (Burt, 1992), and network betweenness (Freeman, 1977), which measures a person's monopoly access to structural holes. ${ }^{[2]}$ Within each of the six companies from which data are drawn for Figure 3A, individual scores on the vertical axis are averaged within five-point intervals on the horizontal axis. The graph shows a familiar nonlinear, downward sloping association in which network brokers (relative to their peers) receive more positive evaluations and recognition, are paid more, and get promoted more quickly to senior positions.

\section{Brokerage and Success for the Chinese Entrepreneurs}

Popular belief distinguishes Asia for its emphasis on the collective over the individual, and success contingent on connections aligned with the formal chain of command. For example, business in Asia can be distinguished by (page references are to the review by Morris, Podolny, \& Ariel, 2000): competition being undesirable within work groups (71), friends being a more likely source of advice and exchange more likely with friends (75), acknowledged friends being more likely to occupy higher statuses (77), and dense networks being more likely to increase felt obligation to help a peer (82). Such claims raise questions about network brokerage, which involves individuals distinguishing themselves from peers to build bridges across groups and chains of command. Thus, brokerage could clash with collectivist local social norms such that returns to brokerage are non-existent or even negative.

Evidence is mixed on the issue. In support of the idea that Chinese culture inhibits brokerage, Yang and Zhang (2015) had difficulty finding structural holes in entrepreneur networks and quote one of their entrepreneurs on fear of failure: 'I try to avoid any potential risks in my way. A vice-president in our company is even more conservative. He stops when he foresees a potential problem. He collects as much information as possible before making any major decisions, and he also tends to exaggerate risks and losses'. Consistent with the quoted sentiment, Batjargal (2010b) reports that networks around Chinese entrepreneurs are smaller and more dense than the networks around Russian entrepreneurs. Ma, Huang, and Shenkar (2011) report that networks rich in structural holes around Taiwanese managers weakened manager ability to identify opportunities, and Xiao and Tsui 
(2007) do not find achievement higher for Chinese employees with larger, more open networks (but see Burt, 2010: 61n).

On the other hand, there is evidence that business practice in China supports brokerage. Batjargal offers a portfolio of studies reporting greater success for Chinese entrepreneurs who have larger networks richer in structural holes (Batjargal, 2007a, 2007b, 2010a; Batjargal et al., 2013; and see Vissa \& Chacar, 2009, for higher performance from Indian entrepreneurs with large, open networks). Merluzzi (2013) reports similar results on Chinese and other Asian managers in a large software company, and Bian and Wang (2016) report cross-sector relations being helpful for raising start-up capital by self-employed respondents in an area probability survey of eight large cities in China. Concluding that returns to brokerage are exceptionally high in China, Batjargal et al. (2013: 1040) summarize as follows their analysis in China and Russia as adverse and uncertain environments (relative to France and the United States): 'entrepreneurs benefit from their network's structural holes. However, those entrepreneurs who operate in settings where the entire institutional order is adverse and uncertain benefit more from their networks' structural holes'.

\section{Summary Evidence}

As predicted by network theory, as found in the West, and as reported across countries by Batjargal et al. (2013), our large-sample evidence shows business success higher in China for entrepreneurs with networks richer in structural holes. Figure 3B shows success higher for entrepreneurs with larger, more open networks (low constraint, to the left in the graph) relative to the success of entrepreneurs with smaller, more closed networks (high constraint, to the right in the graph).

Table 1 contains regression results supporting our conclusion, with correlations in Table 2. We measure business success on multiple dimensions, as we believe an entrepreneur experiences it. We look at sales, jobs, and patents. The idea is that a self-made man is a success to the extent that his business lets him be a big man to the people around him - making it so that (1) a lot of money passes through his hands, (2) jobs can be found for deserving friends, new contacts, or members of their families, and (3) there is some feeling of security from patent protection for the business. We do not assume that the three variables measure the same condition, or that they capture all dimensions to success; only that they are correlated measures of an entrepreneur's success. Each measure is predicted separately in a column of Table 1, then predicted jointly as a z-score composite variable in the fourth column, which is the vertical axis in Figure $3 \mathrm{~B}$.

Beyond the controls for industry differences and the age of a business, the primary predictors of success in Table 1 are whether the founder is still running the business (strong negative association with success), whether the business has a research and development $(\mathrm{R} \& \mathrm{D})$ department (strong positive association with success), and the extent to which there is a small, closed network around the person 
Table 1. Network brokerage and business success

\begin{tabular}{lcccc}
\hline \hline & Number of & & & \\
& Employees & Annual Sales & Business Patents & Business Success \\
\hline Network Constraint (20-100) & -0.391 & -0.320 & -0.995 & -0.440 \\
& $(0.130,-3.01)$ & $(0.166,-1.93)$ & $(0.182,-5.47)$ & $(0.131,-3.36)$ \\
Respondent Is Founder (0-1) & -0.460 & -0.546 & -0.218 & -0.466 \\
& $(0.082,-5.58)$ & $(0.105,-5.17)$ & $(0.102,-2.14)$ & $(0.083,-5.60)$ \\
Firm Age (years since founding, 1-30) & 0.035 & 0.037 & 0.019 & 0.035 \\
& $(0.007,4.95)$ & $(0.009,4.03)$ & $(0.009,2.11)$ & $(0.007,4.83)$ \\
Business Has R\&D Department (0-1) & 0.641 & 0.819 & 1.684 & 0.817 \\
& $(0.066,9.70)$ & $(0.074,9.67)$ & $(0.125,13.46)$ & $(0.067,12.25)$ \\
Electronics Business (0-1) & -0.360 & -0.186 & 0.512 & -0.185 \\
& $(0.108,-3.31)$ & $(.139,-1.34)$ & $(0.156,3.29)$ & $(0.109,-1.69)$ \\
Machinery Business (0-1) & -0.340 & -0.005 & 0.674 & -0.077 \\
Medicine Manufacturing (0-1) & $(0.092,-3.69)$ & $(.118,-0.04)$ & $(0.139,4.86)$ & $(.093,-0.83)$ \\
Transport Business (0-1) & -0.217 & 0.171 & -0.265 & -0.080 \\
Intercept & $(0.119,-1.83)$ & $(0.152,1.12)$ & $(0.205,-1.29)$ & $(0.120,-0.67)$ \\
$\mathrm{R}^{2}$ (pseudo for patents) & -0.21 & -0.158 & 0.231 & -0.164 \\
\hline \hline
\end{tabular}

Notes: Regression results predict each column variable from the row variables for 700 Chinese entrepreneurs. Employees and sales are measured as logs. Business patents vary from zero to 5 or more, and are predicted by a Poisson model. Business success (vertical axis in Figure 3B) is the first principal component combining employees, sales, and patents (describes $65 \%$ of variance in the three indicators). Firm age is 2012 minus the year in which the business was founded. Network constraint is measured as the log of 100 times constraint (horizontal axes in Figure 3). Unstandardized coefficients are presented with standard error and test statistic in parentheses.

running the business (strong negative association with high-constraint networks). It is standard practice to replace founders with managers as a business matures (Wasserman, 2012), so it is not surprising to see that businesses still run by founders are not yet as successful as businesses run by someone other than the founder.

The substantive significance of the R\&D department is not obvious. The success associated with an R\&D department is independent of industry, and the number of years for which the business has been operating, both of which matter but are held constant in Table 1. We thought that a large, open network let an entrepreneur get more success out of having an R\&D department, however, there is negligible difference between the success-network association for businesses that have an R\&D department versus businesses that do not (0.88 t-test for difference when a slope adjustment is added to the fourth column of Table $1, \mathrm{P} \sim 0.38$ ). And although businesses that have an R\&D department are on average larger with higher sales, there are many successful businesses that do not claim R\&D, and many small businesses that do.

We suspect that the difference between businesses with and without an R\&D department is less a difference between businesses than it is a difference between respondents in their perspective on their business. Having an R\&D department is a yes-no response to the following question: 'Does your firm currently conduct its 
Table 2. Means, standard deviations, and correlations for Table 1

\begin{tabular}{|c|c|c|c|c|c|c|c|c|c|c|c|c|c|}
\hline & Mean & S.D. & 1 & 2 & 3 & 4 & 5 & 6 & 7 & 8 & 9 & 10 & 11 \\
\hline 1. Number of Employees & 4.33 & .96 & 1.00 & & & & & & & & & & \\
\hline 2. Annual Sales & 6.95 & 1.22 & 0.77 & 1.00 & & & & & & & & & \\
\hline 3. Business Patents & 0.73 & 1.44 & 0.25 & 0.32 & 1.00 & & & & & & & & \\
\hline 4. Business Success & 0.00 & 1.00 & 0.90 & 0.92 & 0.55 & 1.00 & & & & & & & \\
\hline 5. Network Constraint & 4.01 & 0.25 & -0.11 & -0.07 & -0.09 & -0.12 & 1.00 & & & & & & \\
\hline 6. Respondent Is Founder & 0.80 & 0.40 & -0.25 & -0.24 & -0.08 & -0.23 & 0.07 & 1.00 & & & & & \\
\hline 7. Firm Age & 11.87 & 4.63 & 0.23 & 0.20 & 0.09 & 0.22 & -0.07 & -0.16 & 1.00 & & & & \\
\hline 8. R\&D Department & 0.50 & 0.50 & 0.33 & 0.35 & 0.35 & 0.44 & 0.07 & -0.07 & 0.07 & 1.00 & & & \\
\hline 9. Electronics Business & 0.15 & 0.35 & -0.03 & -0.02 & 0.07 & 0.01 & 0.05 & 0.05 & 0.03 & 0.11 & 1.00 & & \\
\hline 10. Machinery Business & 0.26 & 0.44 & -0.07 & 0.03 & 0.13 & 0.03 & 0.04 & 0.01 & -0.08 & 0.06 & -0.24 & 1.00 & \\
\hline 11. Medicine Manufacture & 0.11 & 0.31 & 0.06 & 0.11 & -0.06 & 0.03 & -0.03 & -0.11 & 0.08 & 0.04 & -0.15 & -0.21 & 1.00 \\
\hline 12. Transport Business & 0.24 & 0.43 & -0.02 & -0.05 & -0.02 & -0.03 & -0.07 & -0.02 & 0.01 & -0.03 & -0.23 & -0.33 & -.20 \\
\hline
\end{tabular}


own R\&D activities or have an R\&D department'? Answers 'yes' include a wide variety of situations, from businesses with multiple people conducting research, down to businesses such as the one in which the R\&D department consisted of a person at a desk scanning into a computer the image on a designer scarf so the company could make inexpensive copies of the scarf. The search for characteristics distinguishing entrepreneurs who claim they have an R\&D department is an intriguing topic. However, the main point for this paper is that, regardless of R\&D department, the success associated with large, open networks in theory and prior research on American and European business leaders is similarly associated with large, open networks around the Chinese entrepreneurs. ${ }^{[3]}$

\section{Evidence without Event Contacts}

Event contacts turn out to be important for predicting business success. Of all 4,464 contacts cited by the entrepreneurs, about a third are named only as event contacts $(1,341)$. The other contacts are current, of whom about half were also named as event contacts (1,564 of 3,123 current contacts).

Limiting networks to current contacts underestimates the size of the networks around the entrepreneurs. The average number of current contacts is 4.46 , which is well below the full number of contacts named (95\% confidence interval of 6.27 to 6.49 around the 6.38 average in Table A2).

Limiting networks to current contacts underestimates access to structural holes. Networks appear more closed than they actually are. The average entrepreneur cites 2.69 nonredundant current contacts, which is well below the full number cited (95\% confidence interval of 3.56 to 3.77 around the 3.66 average in Table A2). Average network constraint computed from current contacts is 0.70 , which is well above the average when all contacts are included in the network $(95 \%$ confidence interval of 0.56 to 0.58 around the 0.57 average in Table A2).

It is not surprising that networks appear more closed when limited to a subset of contacts, and it would not be a problem if the bias were consistent. Open networks would appear a little more closed when limited to current contacts. Closed networks would appear still more closed. Mean network scores would be affected, but regression models using the network scores to predict success need not be affected.

However, the bias is not consistent. Event contacts are included among current contacts in some networks (Figure 1), but not others (Figure 2). The number of current contacts an entrepreneur cites is correlated only 0.16 with the total number of contacts cited. Log network constraint for all contacts, the network variable predicting business success in Table 1 , is correlated 0.57 with log network constraint limited to current contacts.

Table 3 confirms the problem possible: Limiting an entrepreneur's network to current contacts significantly underestimates the network association with business success. The variables in Table 3 are the same as in Table 1, except here network 
Table 3. Current network and business success

\begin{tabular}{lcccc}
\hline \hline & Number of & & & \\
& Employees & Annual Sales & Business Patents & Business Success \\
\hline Network Constraint (20-100) & -0.134 & 0.150 & -0.043 & -0.018 \\
& $(0.122,-1.09)$ & $(0.157,0.96)$ & $(0.180,-0.24)$ & $(0.124,-0.15)$ \\
Respondent Is Founder (0-1) & -0.476 & -0.553 & -0.266 & -0.481 \\
& $(0.083,-5.75)$ & $(0.106,-5.23)$ & $(0.102,-2.60)$ & $(0.084,-5.74)$ \\
Firm Age (years since founding, 1-30) & 0.036 & 0.039 & 0.023 & 0.036 \\
& $(0.007,5.05)$ & $(.009,4.21)$ & $(0.009,2.61)$ & $(0.007,5.00)$ \\
Business Has R\&D Department (0-1) & 0.629 & 0.804 & 1.635 & 0.801 \\
& $(0.066,9.48)$ & $(0.085,9.50)$ & $(0.125,13.09)$ & $(0.067,11.94)$ \\
Electronics Business (0-1) & -0.362 & -0.198 & 0.463 & -0.192 \\
Machinery Business (0-1) & $(0.109,-3.31)$ & $(0.139,-1.42)$ & $(0.155,2.98)$ & $(0.110,-1.74)$ \\
& -0.337 & -0.012 & 0.641 & -0.078 \\
Medicine Manufacturing (0-1) & $(0.093,-3.62)$ & $(0.119,-0.10)$ & $(0.139,4.62)$ & $(0.094,-0.83)$ \\
Transport Business (0-1) & -0.207 & 0.180 & -0.255 & -0.068 \\
& $0(.119,-1.73)$ & $(.152,1.18)$ & $(0.205,-1.24)$ & $(0.121,-0.56)$ \\
Intercept & -0.239 & -.153 & 0.269 & -0.147 \\
R2 (pseudo for patents) & $(0.094,-2.56)$ & $(0.119,-1.28)$ & $(0.150,1.80)$ & $(0.095,-1.55)$ \\
\hline \hline
\end{tabular}

Notes: Regression results predict each column variable from the row variables for 700 Chinese entrepreneurs. These are the same variables used in Table 1, except that the network index here is limited to current contacts (which includes any event contacts who were also cited as current contacts). Unstandardized coefficients are presented with standard error and test statistic in parentheses.

constraint is limited to current contacts. The first row of Table 3 shows consistently negligible associations between success and network. Replacing network constraint with effective size yields the same conclusion. Patents have a nonzero association with effective size, $2.11 \mathrm{t}$-test, but the other three success measures are independent of effective size. More, the results in Table 3 are a conservative test of the importance of event contacts. Respondents were asked the event name generators before they were asked about current contacts, so respondents in the China survey were primed to think about the business in broader historical context than is usually the case when a respondent answers only current contact name generators. About half of the people cited as current contacts were also cited as event contacts, in some measure a reflection of respondents being primed to think about people who have been helpful during significant events. Fortunately, the evidence in Table 3 is clear despite the conservative test: Event contacts are critical to measuring the advantage provided by networks around the Chinese entrepreneurs.

The importance of event contacts replicates a well-known phenomenon in network analysis: relationships gone into remission can be reanimated to advantage. A widely-cited example is Granovetter's (1973) evidence on job search and weak ties. His evidence is about relations gone into remission - out of touch friends from the old neighborhood, out of touch coworkers from previous employers, out of touch classmates. Job seekers found new jobs by contacting 
people they used to know well, but with whom they had lost touch. The relationship reanimated with a friendly call became a bridge across the structural hole between the group containing the job seeker and the group containing the contact. Lee (1969) shows a similar positive result for women searching for an abortionist when abortion was illegal. Levin, Walter, and Murnighan (2011) show a similar positive result for executive MBA students asked to reanimate contact with colleagues not seen for years.

In this light, event contacts beyond an entrepreneur's current contacts are bridges to a past more diverse than the present, making the entrepreneur's network a broader, more reliable source of support in dealing with diverse future events. Our next task is to look inside the relationships. ${ }^{[4]}$

\section{NETWORK GLOSURE AND TRUST}

Closure's association with trust and reputation is another principle that traces back to the golden age of social psychology (Asch, 1951; Festinger et al., 1950). The principle was revitalized with the popularity of network metaphors (Coleman, 1988; Granovetter, 1985, 1992), and enriched with research applications to organizations and markets (Barker, 1993; Bernstein, 1992, 2001; Burt, 2005; Greif, 1989; Uzzi, 1997). The gist of the story is as follows: the more connected the people in a network, the higher the reputation cost for bad behavior, the more likely bad behavior will be detected, so the less likely bad behavior will occur, which lowers the risk of trust, which thereby increases the probability of trust. Applied to the Chinese entrepreneurs, the trust association with closure predicts that entrepreneurs will have more trust in contacts with whom they are embedded in a closed network of mutual contacts. Figure 4 shows the prediction well supported. To avoid confusion between mutual contacts and the contact being evaluated for trust, we discuss mutual contacts as third parties to a relationship.

\section{Glosure and Trust in the West}

The graph to the left in Figure 4 illustrates what we know about the association between closure and trust using data on American and European analysts and bankers (adapted from Burt, 2010: 174-175; cf. Burt, 2005: 197-199, for the same association in reverse showing closure inhibiting relationship decay). The network data in Figure 4A are annual evaluations of colleagues in which the evaluator chooses colleagues to evaluate. The vertical axis indicates the probability that the evaluator chooses to work with a colleague again next year and gives him or her a top evaluation. The horizontal axis varies from left to right with increasing closure this year. To the left, the sociogram beneath the axis shows evaluator and colleague with no mutual contacts (low closure). To the right, evaluator and colleague have many contacts in common (high closure). 

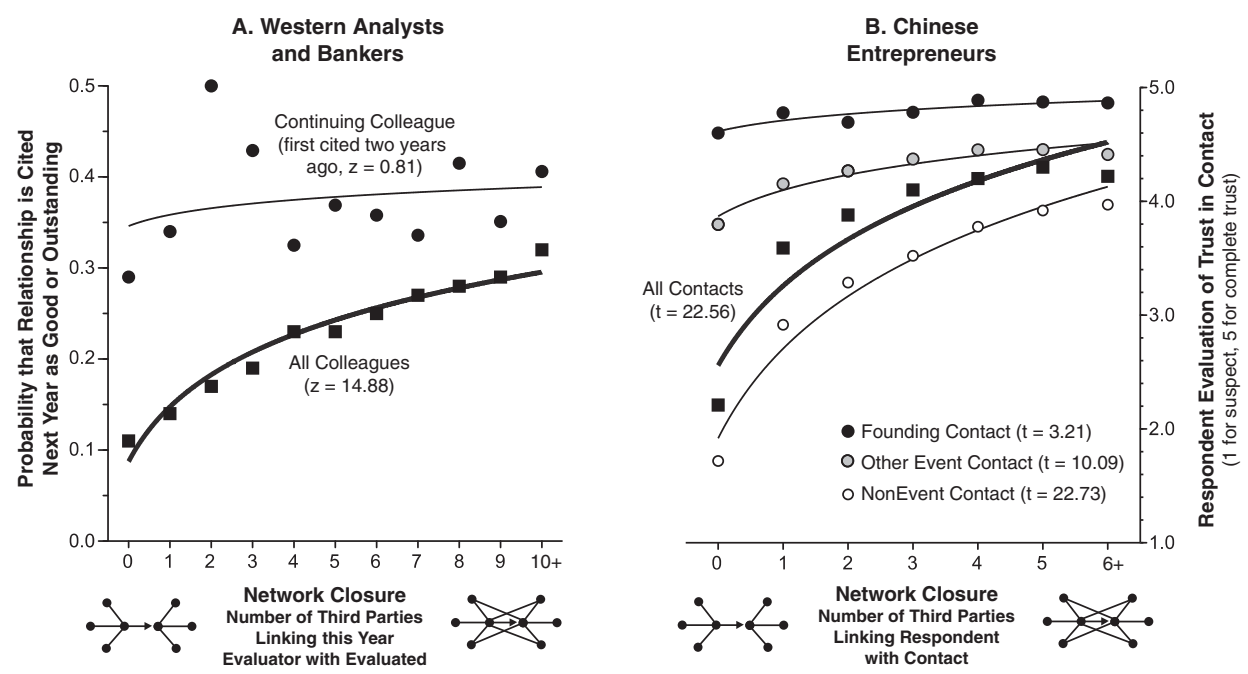

Figure 4. Network Closure and Trust

Notes: Dots are average Y scores at each level of X. Graph A describes 46,231 observed colleague relations with analysts and bankers over a four-year period (adapted from Burt, 2010:174-175). Vertical axis is the proportion of relations cited next year as good or outstanding. Horizontal axis is number of mutual contacts this year. Graph B describes 4,464 relationships cited by the 700 Chinese entrepreneurs. Vertical axis is mean respondent trust in the contact, measured on a five-point scale. Horizontal axis is the number of other people in a respondent's network connected with the contact being evaluated for trust. Test statistics are estimated in both graphs with controls for differences in network size and adjusted for autocorrelation between relationships (Stata 'cluster' option, see Table 4 for estimates with further controls).

Two associations are displayed. Across 46,231 relationships, the bold regression line in Figure 4A describes a strong tendency for the most positive colleague evaluations to occur next year within closed networks this year (logit z-score test statistic of 14.88, $\mathrm{P}<<0.001$, including controls for network size and autocorrelation between evaluations made by the same evaluator). Second, the thin line in Figure 4A shows that once evaluator and evaluated know one another well, closure is irrelevant. The dots at the top of the graph show the association between closure this year and positive evaluation next year - just for the relationships in which the evaluator has been working with the colleague for at least two years. The flat, thin regression line through those dots shows a high probability of positive evaluation, independent of closure embedding the evaluator and colleague (logit test statistic of 0.81 ).

The difference between the bold and thin regression lines in Figure 4A illustrates the difference between what Granovetter (1992) distinguished as 'relational' versus 'structural' embedding. Structural embedding refers to a closed network of mutual contacts, as measured on the horizontal axes in Figure 4. Relational embedding refers to the strength of existing connection between two people when trust is required, which is measured for the bankers and analysts by the years for which evaluator and colleague have worked together; more years, more relational 
Table 4. Network closure and trust

\begin{tabular}{|c|c|c|c|c|c|}
\hline & \multicolumn{3}{|c|}{ Predicting Level of Trust } & \multicolumn{2}{|c|}{ Means } \\
\hline & Coefficient & S.E. & $\begin{array}{c}\text { Test } \\
\text { Statistic }\end{array}$ & $\begin{array}{c}\text { Event } \\
\text { Contacts }\end{array}$ & $\begin{array}{c}\text { NonEvent } \\
\text { Contacts }\end{array}$ \\
\hline Network Size (cited contacts, 3-12) & 0.016 & 0.009 & 1.73 & 6.16 & 6.91 \\
\hline $\begin{array}{l}\text { Closure, Structural Embedding (number } \\
\text { third parties, 0-6) }\end{array}$ & 0.694 & 0.046 & 14.96 & 3.22 & 2.73 \\
\hline Event Contact $(0-1)$ & 1.742 & 0.077 & 22.75 & 10.29 & 19.25 \\
\hline $\begin{array}{l}\text { Interaction (event contact x structural } \\
\text { embedding) }\end{array}$ & -0.616 & 0.052 & -11.86 & 13.22 & 5.50 \\
\hline Frequency (days between contacts, 1-90) & -0.014 & 0.001 & -18.68 & 0.017 & 0.001 \\
\hline Years Known $(1-60)$ & 0.016 & 0.002 & 9.43 & 0.064 & 0.003 \\
\hline Childhood Friend $(0-1)$ & 0.020 & 0.065 & 0.31 & 0.021 & 0.044 \\
\hline Classmate in School $(0-1)$ & 0.051 & 0.072 & 0.72 & 0.083 & 0.006 \\
\hline Co-Member in Business Association (0-1) & -0.284 & 0.107 & -2.66 & 0.039 & 0.005 \\
\hline Family $(0-1)$ & 0.045 & 0.070 & 0.64 & 0.122 & 0.011 \\
\hline Military $(0-1)$ & -0.395 & 0.134 & -2.94 & 0.007 & 0.001 \\
\hline Family $(0-1)$ & 0.045 & 0.070 & 0.64 & 0.122 & 0.011 \\
\hline Military $(0-1)$ & -0.395 & 0.134 & -2.94 & 0.007 & 0.001 \\
\hline Neighbor $(0-1)$ & -0.019 & 0.083 & -0.22 & 0.025 & 0.007 \\
\hline Party $(0-1)$ & -0.288 & 0.107 & -2.70 & 0.015 & 0.003 \\
\hline None of the Above $(0-1)$ & -0.120 & 0.073 & -1.66 & 0.755 & 0.931 \\
\hline
\end{tabular}

Notes: OLS regression results predict trust on a five-point scale (name generator item, Figure A3 in Appendix, $\mathrm{N}=4,464$ relationships, 2.449 intercept, $\mathrm{R} 2=0.60)$. 'Event Contacts' are people cited as most valued during one or more of the significant events in the business ( $\mathrm{N}=2,905$ relations). 'NonEvent contacts' are anyone else ( $\mathrm{N}=1,559$ relations). Contacts could be cited for multiple roles (name generator item, Figure A3 in Appendix, e.g., contact could be 'neighbor' and 'classmate'). Number of third parties is increased by one and logged to capture the nonlinear association in Figure 4 (but means are counts of third parties). Categories of contact frequency are entered in days ( 1 for 'daily', 7 for 'weekly', 30 for 'monthly', and 90 for 'less often'). 'None of the Above' is 1 if contact is none of the seven kinds of contacts listed above. Standard errors are adjusted down for autocorrelation between relations described by the same respondent (Stata 'cluster' option).

embedding. Structural embedding facilitates trust on average (and persistent reputation, Burt, 2005, 2010), but can be irrelevant to trust when two people know each other well, as is the case for the analysts and bankers in Figure 4 after they work with a colleague for two years.

\section{Glosure and Trust for the Chinese Entrepreneurs}

The graph to the right in Figure 4 shows a pattern for the Chinese entrepreneurs very similar to the pattern for the Western analysts and bankers. Trust is more likely within relationships structurally embedded in a closed network, but the highest levels of trust come from relational embedding relatively independent of closure in relations with event contacts. More precisely, Table 4 contains regression results predicting trust measured on a scale from one to five (name interpreter item, Figure A3 in the Appendix) from closure around respondent and contact, controlling for network size and the nature of the respondent's relationship with the contact. ${ }^{[5]}$ 


\section{Summary Evidence}

We note three broad results in Table 4. First, illustrated by the bold line in Figure $4 \mathrm{~B}$, there is a strong, positive association between trust and the number of third parties in which a relationship is embedded (14.96 t-test). This result corresponds to the bold line in Figure 4A through analyst and banker relations. The result holds across the five industries, ${ }^{[6]}$ across the three geographic regions, ${ }^{[7]}$ if the closure measure in Figure 4B is replaced with a continuous measure of connection strength, ${ }^{[8]}$ or if the five response levels of trust are treated as ordinal rather than interval..$^{[9]}$ Entrepreneurs vary significantly in their average level of trust, but have in common their tendency to trust more within more embedded relationships.

\section{Evidence Distinguishing Event Contacts}

The example networks in Figures 1 and 2 put the closure-trust association in broader perspective. Consistent with closure facilitating trust, the entrepreneur in Figure 1 has high trust in two people: contacts 1 and 2. The two contacts are members of the entrepreneur's family, and are well connected to others in the core network around the entrepreneur. The entrepreneur in Figure 2 is more complicated. He expresses high trust in eight of his ten contacts, none of whom are family. Trust in the neighbor who helped him found the business (contact 1) makes sense in terms of closure because he has known the neighbor for 35 years and their relationship is embedded in mutual connections with four other people in the network. But the entrepreneur also expresses high trust in contact 6 , a relationship embedded in only two third parties, to a person the entrepreneur has only known for a few years.

What the two trusted contacts have in common is that they are event contacts, which is the second result we note in Table 4: trust in event contacts is relatively independent of closure. Event contacts are trusted regardless of how long the entrepreneur and contact have known each other - almost two points higher on a five-point scale (coefficient of 1.742, yielding a 22.75 t-test) - and the 0.694 trust-closure association for nonevent contacts almost disappears for event contacts $(-0.616$ decrease, $-11.86 \mathrm{t}$-test, second row of Table 4$) .^{[10]}$ The change in association is illustrated in Figure $4 \mathrm{~B}$ by the thin lines through the solid dots at the top of the graph being flatter than the thin line through the hollow dots low in the graph. The two thin lines in Figure $4 \mathrm{~B}$ describing high trust in event contacts correspond to the thin line in Figure 4A describing high trust in colleagues with whom an analyst or banker has worked for more than two years. ${ }^{[1]}$

Table 5 connects our focus on event contacts with our prior focus on current contacts when predicting business success in Table 3. Rows in Table 5 distinguish contacts named on event name generators (name generator items one and two in Table Al in the Appendix). Columns distinguish contacts named on the current 
Table 5. Trust in event contacts versus current contacts

\begin{tabular}{lcc}
\hline \hline & Current Contacts & Other \\
\hline Event Contacts & $4.463(1,564)$ & $4.292(1,341)$ \\
Other & $3.069(1,559)$ & - \\
\hline \hline
\end{tabular}

Notes: Cells contain average trust score on a five-point scale (name generator item, Figure A3 in Appendix, $\mathrm{N}=4,464$ ) with number of relations averaged in parentheses. Current contacts are people cited on one or more of the name generators three to six in Table Al in the Appendix. Event contacts are people cited on either of the two event name generators, one or two in Table Al.

name generators (name generator items three through six in Table Al). We focused on the column contrast for predicting business success in Table 3 because we wanted to know what was gained by adding event name generators to the items usually used to define a business leader's current network. However, mean trust scores in the cells of Table 5 show that trust in event contacts is high with or without also being cited as current contacts. Therefore, we shift in this section to the row contrast when predicting trust. In fact, a dummy variable distinguishing current contacts (the column contrast in Table 5) is a negligible addition to the trust prediction in Table 4 (1.68 t-test, $\mathrm{P} \sim 0.09$ ).

\section{Trust in Contacts Beyond Traditional Sources}

The remaining predictors in Table 4 are controls for the substance of relationships. The most consequential are frequency (how frequently a contact is met) and duration (how long the contact has been known). Trust is lower in people rarely met and higher in people long known (-18.68 and 9.43 t-tests respectively). Frequency is the more consequential in practice. Trust drops one point on the five-point scale for slightly more than a two-month delay between meetings with a contact $(1.0$ divided by -0.014 coefficient is 71 days). To get the same increase in trust through years known, the entrepreneur would have to know someone for a lifetime (1.0 divided by 0.016 coefficient is 63 years).

Note how few of the cited contacts come from traditional sources. This is the third result we highlight in Table 4. Perhaps reflecting the lack of institutional support for private enterprise when entrepreneurial business began blossoming in the region, entrepreneurs are unlikely to cite contacts in the military and contacts in the Communist Party $(-2.94$ and -2.70 t-tests respectively with trust). Of 4,464 contacts, only 69 , or $1.6 \%$, are affiliated with the military or party. Entrepreneurs are more likely to turn to traditional sources during a significant event (e.g., 12.2\% of event contacts are family versus $1.1 \%$ of nonevent contacts), but people from traditional sources are no more likely to be trusted than other contacts once embedding and events are held constant (e.g., 0.64 t-test for trust in family contacts). 
Far and away, the most likely source of contacts is somewhere beyond the usual seven listed in Table 4. Seventy five percent of event contacts are from a source unknown. The percentage is $93.1 \%$ for nonevent contacts. A source unknown means the contact is not a childhood friend, not a classmate, not family, not a person met in the military, not a neighbor, and not a member of the party - which is a lot of things the contact is not. All together, $81.7 \%$ of the contacts are people from sources unknown. ${ }^{[12]}$

The prevalence of contacts from unknown sources reinforces the point that events are critical to trust. On average, the contacts we cannot assign to a source are neither trusted nor distrusted ( -1.66 t-test in Table 4). However, they are the most likely source for help during a significant event, and their help during the event results in an entrepreneur's trust. This is again affirmation of Nee and Opper's (2012) argument about the rise of capitalism from below. Formal institutions were not available to help the entrepreneurs build their businesses. The entrepreneurs built their own support institutions, along-side their businesses; in the form of a network of people they knew they could trust - often people outside the usual sources for trusted contacts.

\section{GONGLUSIONS AND GUANXI}

We believe the results clear space for rigorous integrative research bridging theory and research on the roles social networks play in Chinese and Western business. In service of that belief, we highlight four broad conclusions from the results.

\section{Network Brokerage and Success}

Our first conclusion is that access to structural holes is a competitive advantage in China as in the West. Of course, there are contingencies for the association between brokerage and success, as there are in the West, and there might be contingencies unique to China. That is a subject for future research, as it has been for the last twenty years in the West. Our conclusion remains, illustrated in Figure 3, that the success associated with large, open networks in theory and prior research on American and European business leaders is similarly associated with large, open networks around Chinese entrepreneurs.

We also learned that much of an entrepreneur's brokerage potential lies beyond his or her current network - in strong, trusting connections with people who helped the entrepreneur through a significant business event. At least half of the 'event' contacts are beyond the current network. The results in Table 3 show that ignoring event contacts beyond the current network eliminates the evidence of success higher with large, open networks. This has implications for standard research practice, which is to gather data on the current network around a business leader. It could be that the importance of event contacts for the Chinese entrepreneurs also occurs in the West, whereupon returns to brokerage 
in the West have been significantly underestimated. Or, the importance of event contacts is unique to China because of the more intimate role that history plays in Chinese culture. Either way, event contacts are a promising subject for future research.

\section{Network Closure and Trust}

Our second conclusion is that trust is facilitated within closed networks in China as in the West. The similarity is clear in Figure 4, with trust reaching higher levels as a relationship is more structurally embedded, then breaking free of the embedding when a relationship is well established. Trust is a familiar topic in studies of Chinese business, but it is a welcome sight to see such a familiar pattern to the network correlates of trust. Here again, Table 4 provides contingency factors regarding contact frequency and years known, but the most interesting trust result that warrants future research is the high trust in event contacts drawn from sources unknown - which leads to our third conclusion.

\section{Guanxi Ties}

Our third conclusion is a caution on the second, concerning overlap between East and West on the subject of guanxi. Business networks in China are often discussed as guanxi, referring to the kinds of relations believed to be less prevalent in the West. Guanxi is a colloquial term that has immediate face validity, and provides grounds for rich discussion (Hwang, 1987). The gist of the image is that guanxi relations involve three qualities: (1) familiarity, intimacy, (2) trust, and (3) mutual obligation (Bian, 1997; see Bian, forthcoming, for analytical review of the literature; see Luo, Huang, \& Wang, 2011, for meta-analysis; and Chen, Chen, \& Huang, 2013, for broader review). Luo (2011, 2016; Luo \& Cheng, 2015; Luo, Cheng, \& Zhang, 2016) adapts the imagery to discuss 'guanxi circles' in Chinese management. Guanxi circles are in some ways akin to familiar center-periphery images of networks layers in the 'social atom' around a person (Moreno, 1947), or an 'inner circle' of business elites (Useem, 1984) - but the concept of a guanxi circle is more precise with respect to the role of trust and obligation for network advantage, so we adopt it here to discuss the Chinese entrepreneurs (see Guo \& Miller, 2010: 285, for an image of entrepreneur networks related to Luo's image of a guanxi circle). At the center of Luo's guanxi circle is an inner ring of real and pseudo family members. This ring of guanxi applies 'need rules' in which family ties are used to more or less satisfy each other's needs without asking for return. Luo's guanxi circle then expands from inner ring to a middle ring composed of good friends connected by longterm favor exchanges, where both parties combine expressive and instrumental exchanges and carefully maintain trustworthiness under the principle of reciprocity. Beyond the middle ring are acquaintances on the periphery, where instant return and bargaining in social exchanges are allowed. The 'equity rule' is that trust comes 
from fair exchanges following generally accepted norms. Beyond the periphery boundary there are no rules. Trust would be perilous. Our data on the Chinese entrepreneurs focus us primarily on relations toward the center of the guanxi circle, but it is clear that a relationship can be more or less guanxi depending on the level of trust and obligation within the relationship.

The critical issue for empirical research is defining guanxi. Colloquial terms, such as guanxi, are often fraught with multiple meanings so they can be difficult to use with sufficient precision for research. One way to move forward is to agree on the wording to be accepted as a definition of guanxi. This facilitates communication among researchers, but does little to connect that communication to empirical research, or to new scholars entering the area. Another way to move forward is to identify construct validity criteria for a relationship that is guanxi. Here is a network definition of guanxi based on construct validity characteristics in Table 4: A relationship is a guanxi tie to the extent that trust is high and relatively independent of social structure around the relationship. For the analysts and bankers in Figure 4, such guanxi ties are with colleagues with whom they have worked for two or more years (cf., Bian \& Zhang, 2014: 428-429, comparing guanxi to strong ties inside 'oldboy networks' in the West). For the Chinese entrepreneurs in Figure 4, such guanxi ties are with personal contacts who provided valued support through a significant event for the entrepreneur's business.

The analysts, bankers, and Chinese entrepreneurs in Figure 4 all have guanxi ties by the above network definition, but they differ in the extent to which they have guanxi ties. For the analysts and bankers, less than a tenth of their colleague relationships qualify as guanxi (1,233 colleagues with whom they have worked for the last two years in a population of 13,780 colleagues in the third-year panel who could have been cited as two-year colleagues). For the Chinese entrepreneurs, two thirds of their key contacts qualify as guanxi (2,905 event contacts in a population of 4,464 cited contacts).

Of course, people working in a large financial organization within a supportive business environment are fundamentally different from the Chinese entrepreneurs who built their businesses when such activity was viewed with suspicion. And of course, network data were collected in different ways in the two populations. The analysts and bankers were asked about their current contacts, some of whom are colleagues and are long standing. The Chinese entrepreneurs were asked explicitly to look back over the history of their business to name event contacts in that history.

However, some event contacts named by the Chinese entrepreneurs are relatively new acquaintances, the trust results in Table 1 exist with years known held constant, and the prevalence of guanxi ties is so different in the two populations that it warrants note. The actual difference is an empirical question, but suppose there is some truth to the dramatic difference we observe. With guanxi ties a larger presence in the Chinese networks, it is understandable that scholars would talk about Chinese networks being fundamentally different from the networks 
Table 6. Founding is a guanxi event

\begin{tabular}{lrrr}
\hline \hline & \multicolumn{2}{c}{ Predicting Level of Trust } \\
\cline { 2 - 4 } & Coefficient & S.E. & Test Statistic \\
\hline Closure, Structural Embedding (number third parties, 0-6) & 0.711 & 0.047 & 15.26 \\
Contact Cited in Founding & & \\
Level Adjustment (event dummy, 0-1) & -0.077 & 0.091 & 22.77 \\
Slope Adjustment (event dummy x structural embedding) & 0.059 & -10.80 \\
Contact Cited in Subsequent Event & 1.680 & 0.078 & 21.43 \\
Level Adjustment (event dummy, 0-1) & -0.591 & 0.054 & -10.85 \\
Slope Adjustment (event dummy x structural embedding) & & &
\end{tabular}

Notes: OLS regression results predict trust on a five-point scale (name generator item, Figure A3 in Appendix, $\mathrm{N}=4,464$ relationships, 2.340 intercept, $\mathrm{R} 2=0.61$ ). The regression model includes all of the controls in Table 4. Standard errors are adjusted down for autocorrelation between relations described by the same respondent (Stata "cluster" option).

around managers in the West. Still, it is productive to acknowledge the similar trust correlates of network structure in the two business environments: the network closure provided by structural embedding facilitates trust on average, presumably through reputation costs, and certain relationships emerge as guanxi ties within which trust is high and relatively independent of structural embedding. The proposed perspective on guanxi ties allows that networks in China operate in ways different from networks in the West, not because they are different in theory, but because they are different in composition. Within component kinds of relationships - bridges, embedded bonds, or guanxi - network mechanisms work the same way in East and West. The proposed network image of guanxi ties seems a productive vantage point for identifying network mechanisms in China that are well understood in the West, and identifying network characteristics in the West that are more abundantly available for study in China.

\section{Guanxi Events, Places, and People}

Continuing with the network definition of guanxi, kinds of events can be distinguished by the extent to which they generate guanxi ties. For example, a contact who helped replace a failed critical supplier could be seen as more of a guanxi tie than a person who helped find a new accountant. We have not studied the content of the events cited by the Chinese entrepreneurs, but we do know which contacts were cited for their help in founding the business (versus contacts who helped in subsequent events).

Table 6 contains trust prediction results distinguishing founding from the other events. Contacts cited for help during the business founding are more trusted (2.077 versus 1.680 coefficients), and trust in them is less dependent on closure (0.711 0.636 leaves a 0.075 coefficient for trust increasing with closure for a founding contact, versus a stronger 0.120 coefficient describing trust more dependent on 
closure for other event contacts). These results are illustrated in Figure 4B by the thin line for founding contacts being higher and flatter than the thin line for other event contacts. In other words, founding is an example guanxi event.

In the same way that events can be distinguished for the extent to which they generate guanxi ties, any category of people or relationships can be distinguished for the extent to which business in the category is characterized by guanxi. Nanjing is an example. We report, in footnote 7 , no regional differences in the average level of trust or closure's association with trust. That is true, but only when we hold Nanjing constant. The other two sample cities in Jiangsu province look like cities in the other two provinces, but Nanjing stands apart. Contacts are more trusted by entrepreneurs in Nanjing (2.47 t-test for higher trust in Nanjing) and that trust is less dependent on structural embedding $(-2.08 \mathrm{t}$-test for the Table 5 slope adjustment in Nanjing). A positive level adjustment and negative slope adjustment are the two network criteria for guanxi ties, which makes Nanjing the sample city in which guanxi is most characteristic of entrepreneur relationships.

Kinds of people can be more prone to guanxi ties. For example, we checked for gender differences in trust by adding three dummy variables to Table 4: respondent is female, contact is female, and both respondent and contact are female (homophily). Women are slightly more likely to trust, be trusted, and trust one another, but all three associations are statistically negligible $\left(\mathrm{F}_{(3,699)}=2.15\right.$, $\mathrm{P} \sim 0.09)$. The slope adjustment for women trusting women is negligible $(0.95$ t-test, $\mathrm{P} \sim 0.34$ ), but there is a significant decrease in the trust facilitated by closed networks: trust from female entrepreneurs is less associated with structural embedding, and trust in female contacts is less associated with structural embedding $\left(\mathrm{F}_{(2,699)}=4.02, \mathrm{P} \sim 0.02\right)$. In other words, women are more prone to guanxi ties. Trust is slightly higher with women, and significantly less dependent on structural embedding - perhaps because they do not, or cannot, rely as much on reputation costs to lower uncertainty in their relations with men. The gender associations are weak relative to our main findings, but it is an interesting note for future research.

\section{Guanxi Over Time}

In a suggestive piece of work, Guo and Miller (2010) study six entrepreneurial ventures in China to draw inferences about how networks around Chinese ventures change as a business develops. At the heart of their inferences is an assumption that the network expands from a stable core (Guo \& Miller, 2010: 284): 'the guanxi ties in the core circle remain highly stable over the venturing process, and it is the periphery circle that experiences constant change and continuous expansion'. The assumption is consistent with other discussions of guanxi expanding from a central core (e.g., Chen \& Chen, 2004), and the imagery is at least implicit in any discussion that draws analogy between guanxi and family (such as Luo on guanxi circles), since family ties continue through time regardless of how members of the 
Table 7. Founding contacts persist at the center of the network

\begin{tabular}{|c|c|c|c|c|c|}
\hline & \multicolumn{2}{|c|}{ Founder Respondents } & \multicolumn{2}{|c|}{ Not Founders } & \multirow[b]{2}{*}{$\begin{array}{c}\text { All } \\
\text { Respondent }\end{array}$} \\
\hline & $\begin{array}{c}\text { Older } \\
\text { Businesses }\end{array}$ & $\begin{array}{c}\text { Newer } \\
\text { Businesses }\end{array}$ & $\begin{array}{c}\text { Older } \\
\text { Businesses }\end{array}$ & $\begin{array}{c}\text { Newer } \\
\text { Businesses }\end{array}$ & \\
\hline \multicolumn{6}{|l|}{ Founding Contacts } \\
\hline Trust (1-5) & 4.80 & 4.81 & 4.79 & 4.74 & 4.80 \\
\hline Third Parties (0-6) & 3.14 & 2.96 & 3.60 & 3.00 & 3.10 \\
\hline Days between Contacts & 5.26 & 5.65 & 5.96 & 6.89 & 5.65 \\
\hline Years Known & 24.28 & 17.76 & 19.39 & 17.89 & 20.27 \\
\hline Percent Family & 36.03 & 31.09 & 20.24 & 29.82 & 31.43 \\
\hline \multicolumn{6}{|l|}{ Other Event Contacts } \\
\hline Trust (1-5) & 4.20 & 4.26 & 4.41 & 4.22 & 4.25 \\
\hline Third Parties (0-6) & 3.21 & 3.21 & 3.61 & 3.22 & 3.26 \\
\hline Days between Contacts & 12.76 & 11.93 & 9.94 & 9.45 & 11.76 \\
\hline Years Known & 12.98 & 9.43 & 11.80 & 9.67 & 10.99 \\
\hline Percent Family & 5.97 & 5.94 & 7.66 & 4.89 & 6.08 \\
\hline \multicolumn{6}{|l|}{ NonEvent Contacts } \\
\hline Trust (1-5) & 3.11 & 3.00 & 3.22 & 2.99 & 3.07 \\
\hline Third Parties (0-6) & 2.67 & 2.64 & 3.15 & 2.79 & 2.73 \\
\hline Days between Contacts & 18.50 & 20.03 & 20.83 & 15.51 & 19.21 \\
\hline Years Known & 6.26 & 4.73 & 5.86 & 5.52 & 5.51 \\
\hline Percent Family & 1.22 & 0.91 & 0.99 & 1.61 & 1.09 \\
\hline
\end{tabular}

Notes: These are means on the five variables (from Table 4) for column respondents citing the row contacts. Founders are respondents responsible for creating the business. 'Not Founders' are respondents who entered later, including many who currently own all or part of the business. Older and newer businesses are distinguished at the median age of 11 years (after 2000). 'Other Event Contacts' are contacts cited as most valued for any events other than the business founding. 'NonEvent Contacts' are current contacts who are not cited on any event name generators.

family feel about each other. Nevertheless, family ties between individuals vary in strength over time, and recent research shows that certain kinds of change in management networks are common, and can be productive. Productive relations can show high decay or churn (Burt, 2005: 196ff.; Quintane \& Carnabuci, 2017), relations allowed to fall into remission can be productively reanimated (Levin, Walter, \& Murnighan, 2011), and advantage can depend on networks oscillating between closed and open (Burt \& Merluzzi, 2016).

Is the presumed stability of core guanxi a characteristic of the networks around Chinese entrepreneurs, or is it an unexamined functionalist assumption (as was common in early network analysis, see Burt \& Merluzzi, 2016)? Results in Table 7 support the image of a stable core. We know from the results in Tables 4 and 6 that event contacts qualify as guanxi ties, especially contacts helpful in founding the business. The three panels in Table 7 distinguish contacts involved in founding the business (core guanxi), from event contacts not involved in the founding (guanxi), from nonevent contacts (mixture of guanxi and other relationships). Columns in Table 7 distinguish kinds of respondents citing the row contacts. Founders are distinguished from respondents who later rose to run the business. The former actually knew the contact cited as valued in founding the business, while the latter 
could be operating on stories they heard about the founding. Then, respondents in older businesses are distinguished from respondents in newer businesses, since the former have had more opportunities to replace old contacts as the business evolved. Our inference from the means in Table 7 is that trust moves up the rows toward the core of an entrepreneur's guanxi (as already established in Table 6), but founding contacts continue to be in frequent contact with the founder and other respondents (few days between contacts), and it is the founding contacts with whom respondents have their oldest relations, and it is the founding contacts who are most likely to be members of the respondent's family. In short, the results in Table 7 support the image of a stable inner core to the networks, anchored on family and founding the business - though clearly not for every entrepreneur since only a third of founding contacts in Table 7 are family. ${ }^{[13]}$

\section{High-Quality Network Data Are a Practical Reality}

Pursuing the above research ideas requires data of a quality similar to, or higher than, the data we have on the Chinese entrepreneurs - which makes our data themselves noteworthy. On a scale of cost and analyses made possible, we have what can be termed 'level-three' network data in that they measure connection strength with and among named contacts. This is the usual level of network data used for research on brokerage and closure because one needs to know connections between contacts to distinguish brokerage bridge relations from relations embedded in a closed network. Higher, 'level-four' data, would be continuous-time behavioral data on connection strength with and among contacts (e.g., the sociometer data in Ingram \& Morris, 2007, or the email networks in Kleinbaum \& Stuart, 2014; Goldberg, Srivastava, Manian, Monroe, \& Potts, 2016), but level-four data are still rare today.

A common strategy in area probability surveys is to gather network data of a more limited kind at lower cost than the level-three data analyzed in this paper. What can be termed 'level-two' network data measure connection strength with named contacts, but ignore connections between contacts. Level-two data alone cannot be used to study brokerage and closure because the inter-contact relations need to be known to distinguish bridges from embedded ties. The limitation can be overcome when level-two data are combined with network structure from outside the survey. Examples are analyses of relations across occupational and other stratification categories using Lin's popular 'positional' network data (e.g., Lin, Ensel, \& Vaughn, 1981; Lin \& Erickson, 2008), or the tradition in management research of analyzing the strength of social relations across boundaries between groups in the formal organization of a company (e.g., Allen \& Cohen, 1969; Tortoriello \& Krackhardt, 2010).

At lower cost, 'level-one' network data are measures of average connections with unnamed contacts in broad categories of kinds of contacts. These data offer a quick, inexpensive sense of how the respondent views his or her network. There 
are many, many examples. On a rating scale of low to high, respondents are asked how much they agree with statements such as: 'My network is as effective as any at my level within the company' (Burt, 1998: 34); 'Please circle the number best describing the extent to which top managers at your firm have utilized personal ties, networks, and connections during the past three years with top managers at supplier firms' (Peng \& Luo, 2000: 501); 'I am good at the art of networking' (Batjargal, 2010a: 145); 'I play a bridging role in the exchange of information and resources among my network ties' (Yang \& Zhang, 2015), or the four-point General Social Survey ersatz density item: 'Some people have friends who know one another. Other people have friends who don't know one another. Would you say that all your friends know one another, most of your friends know one another, only a few of your friends know one another, or none of your friends know one another'? (Burt, 1987: 76).

Ease and cost are the virtues of level-one data. Low validity is the disadvantage. Level-one data are more precisely data on respondent opinions about their network. Absent concrete people and relationships, it is difficult to know how respondents differ in aggregating people and relations to make a summary network evaluation. Cost and validity issues were at the center of the debate in the mid-1980s about whether to gather level-three network data in the General Social Survey (GSS). Adding network items would mean that the GSS could provide network data on a national probability sample of Americans, but with unknown validity, at considerable cost, and unknown respondent fatigue. The most compelling precedent at the time was Fischer's (1982) use of network items with a heterogeneous area probability sample of the San Francisco Bay area, but no one had implemented network items with a national probability sample such as the GSS. Experienced survey researchers preferred to begin with level-one data - ask respondents to evaluate, on a scale of 1 to 4 , how connected their friends were to one another (the ersatz density item quoted above). After much back and forth, the final decision was to include items to gather level-one and level-three network data so the cost-benefit question could be answered in an authoritative way. As it turned out, respondent perceptions of the density of their network had no correlation with the actual density (Burt, 1987). Later work replicated the point that manager opinions about their network advantage have no correlation with their actual network, or the advantage their network provides (Burt, 1998: 32).

Similarly, respondent opinion about using guanxi has no correlation with the actual networks around the Chinese entrepreneurs. Figure 5 illustrates the point. The horizontal axis in the Figure 5 graph is the network constraint index used in Table 1 and Figure 3 to distinguish Chinese entrepreneurs in open (left) versus closed (right) networks. The vertical axis is a popular measure included on the survey of the Chinese entrepreneurs asking for the extent to which the respondent's people network with contacts in business and government. Specifically, following Peng and Luo (2000), respondents were asked to pick a number from 1 to 7 for 'very little' to 'very much' describing 'the extent to which top managers at 


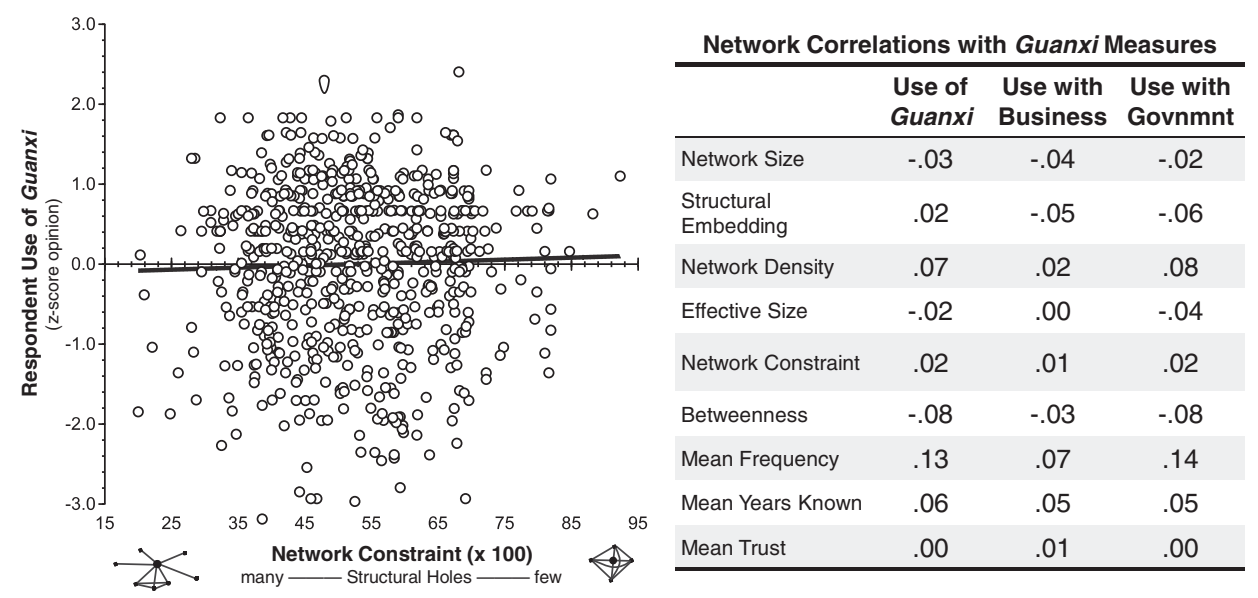

Figure 5. Respondent opinion about guanxi is independent of actual network

Notes: The vertical axis in the graph is the first principal component of six opinion items (capturing $50 \%$ of item variance) asking the respondent about guanxi use during the past three years with suppliers, customers, and competitors (three items) and with political government, industrial authorities, and other government authorities (three items). The other two columns in the table are the average of the three business items, then the average of the three government items. The network measures in the rows of the table are given in Table A2 in the Appendix, except for average levels of frequency, duration, and trust, which are from Table 4. Correlations with network constraint are with the log of 100 times network constraint, the index used to predict business success in Table 1.

your firm have utilized personal ties, networks, and connections during the past three years with top managers at' supplier firms, customer firms, and competitors (three items) and transactions with political government, industrial authorities, and other government authorities (three items). The vertical axis in the graph is the first principal component of all six items (capturing $50 \%$ of item variance). The graph shows no association between respondent opinion about network use and the actual network around the respondent. The table to the right in Figure 5 shows the same lack of association with popular network measures, in addition to the lack of correlation with contact frequency, years known, or trust. One could say that the guanxi measures are about network use rather than network structure, but it is odd to see that people with larger, more open connections make no more or less use of those connections than the people limited to small, closed networks. It seems odd to see people with more trusted contacts making no more or less use of contacts than people with little trust in their contacts. It seems odd that respondent opinion about using business and government guanxi is a negligible addition to predicting business success in Table $1\left(\mathrm{~F}_{(2,689)}=1.86\right.$ for fourth column, $\mathrm{P} \sim 0.16)$. We interpret the negligible correlations as replications of earlier findings that respondent opinion about the structure or value of their network says little or nothing about the actual structure or advantage of the network around them. Scholars interested in understanding the role that networks play in business would do well to upgrade from level-one network data to level-two, or ideally, level-three data. Fortunately, the characteristics and construct validity of the data gathered on 
the Chinese entrepreneurs make it clear that scholars interested in Chinese network data can obtain it at high quality.

\section{NOTES}

Ronald Burt is grateful to the University of Chicago Booth School of Business and Bocconi University for financial support during the work reported here. Katarzyna Burzynska is grateful to the Knut Wicksell Centre for Financial Studies, Lund University, for support during the work reported here. We are both grateful to the Jan Wallander and Tom Hedelius Foundation for the grant to Sonja Opper that funded the fieldwork in China providing the data analyzed here. We are grateful to Yanjie Bian, Arie Lewin, Jar-Der Luo, and Sonja Opper for their comments on an initial draft, to Thomas Burt for editorial assistance, to Sonja Opper for sharing her guanxi measures for Figure 5 (from Opper, Nee, and Holm, forthcoming), and we are grateful for incorporated comments during the 2016 Management and Organization Review 'Research Frontiers Conference', hosted in Beijing by the Guanghua School of Management, Peking University. This manuscript, and network instrument (in English), are available online: http://faculty.chicagobooth.edu/ronald.burt/research.

[1] GDP and import-export data are taken from www.chinadataonline.org. City memberships in Shanghai Economic Area and Yangtze River Delta Economic Coordination Association are taken from a Wikipedia discussion of the two organizations as of November 6, 2016.

[2] We prefer constraint for comparing our results on the Chinese entrepreneurs to prior research, but the usual high correlations among alternative measures also occur across the 700 Chinese entrepreneurs. The log network constraint measure used to predict Chinese success in Table 1 is correlated -0.89 with effective size, -0.80 with betweenness, and the two alternatives are correlated 0.89 with one another.

[3] When gender is added to the prediction of business success in Table 1, women run slightly larger businesses, and their network matters more for business success, but neither association is individually or together statistically significant $\left(\mathrm{F}_{(2,689)}=1.40, \mathrm{P} \sim 0.25\right)$. Women have more female contacts $(25.60 \%$ versus $16.49 \%$ for men), but adding percent female contacts to Table 1 does not improve the prediction of business success $(-0.19$ t-test, $\mathrm{P} \sim 0.85)$.

[4] The lack of network association in Table 3 for current contacts raises a question about prior research on Chinese entrepreneurs that reports success correlated with large, open networks of current contacts. We have had industry proposed as an explanation. For example, Batjargal's (2007a, 2007b, 2010) evidence describes software and internet entrepreneurs in Beijing, which is a business arena more modern and connected to the West than the machinery, textiles, and transport industries in which many of our entrepreneurs work. However, the successnetwork associations in Table 3 do not differ significantly between the five industries from which we draw entrepreneurs. Slope adjustments within each industry are negligible for the success measures in Table 3: for number of employees $\left(\mathrm{F}_{(4,687)}=1.29, \mathrm{P} \sim 0.27\right)$, for volume of annual sales $\left(\mathbf{F}_{(4,687)}=1.75, \mathrm{P} \sim 0.14\right)$, for patents $(7.66$ chi-square, 4 d.f., $\mathrm{P} \sim 0.10)$, and for composite business success $\left(\mathrm{F}_{(4,687)}=1.10, \mathrm{P} \sim 0.36\right)$. While the absent success-network association in Table 3 is consistent across our five industries, it could still exist for Batjargal's software industry in Beijing, which is an industry different from all five of ours.

[5] It might seem inconsistent to use a summary network index to predict success in Table 1, then a summary and dyad index to predict trust in Table 4. Trust is a within-respondent phenomenon that varies across individual relationships so we need a summary network index to characterize the respondent and a dyad index to characterize each individual relationship within which trust is measured. If we had success measured at the level of individual relationships, we would predict success with both summary and dyad network measures, but we only have success measured for the respondent's network as a whole. We could use fixed effects to remove individual differences for the Table 4 prediction, but we wanted to see the trust association with network differences between individuals and contacts. If we re-estimate Table 4 with fixed effects, instead of controlling for network size, we still find trust increasing with closure around nonevent contacts (0.814 coefficient, $16.47 \mathrm{t}$-test), and trust in event contacts significantly higher and less dependent on closure (1.599 and -0.569 coefficients for level and slope adjustments, with respective t-tests of 16.71 and -9.11$)$.

[6] To test for industry differences, we added to Table 4 four dummy variables distinguishing the five industries. Average level of trust does not differ between the industries $\left(\mathrm{F}_{(4,699)}=0.97, \mathrm{P} \sim\right.$ $0.42)$, nor does the closure association with trust $\left(\mathrm{F}_{(4,699)}=1.53\right.$ for industry slope adjustments, $\mathrm{P} \sim 0.19)$. 
[7] To test for differences between the regions (Jiangsu, Shanghai, and Zhejiang), we added to Table 4 two dummy variables distinguishing the regions. Average level of trust does not differ between the regions $\left(\mathrm{F}_{(2,699)}=0.51, \mathrm{P} \sim 0.60\right)$, nor does the closure association with trust $\left(\mathrm{F}_{(2,699)}=2.36, \mathrm{P} \sim 0.10\right)$, but Nanjing stands out as a city more characterized by guanxi (explained below after guanxi is discussed, see 'guanxi events and places' at the end of the paper).

[8] The count of third parties embedding the relationship between respondent and contact $j$ is the sum $\Sigma_{\mathrm{k}} \mathrm{z}_{\mathrm{rk}} \mathrm{z}_{\mathrm{kj}}$ across contacts $\mathrm{k}$ other than $\mathrm{j}$, where relations are treated as binary $(0$ for distant, 1 for anything stronger). Replacing binary measures with the fractional measure of relation strength in Figure A4, the count of third parties can be replaced with a continuous measure of the strength of indirect connection between respondent and contact through third parties. The $\mathrm{R}^{2}$ of 0.597 for the prediction in Table 4 only increases to 0.602 with the continuous measure, and the pattern of results is the same as the pattern in Table 4.

[9] The $14.96 \mathrm{t}$-test in Table 4, and $-11.86 \mathrm{t}$-test for the slope adjustment to closure's association with trust in event contacts, are respectively 11.64 and $-6.98 \mathrm{z}$-scores in an ordinal logit model predicting trust.

[10] The strong trust-closure association for nonevent contacts almost disappears for event contacts, but not quite. In place of the level and slope adjustments for event contacts in Table 4, imagine a model in which the level and slope adjustments are for nonevent contacts. Trust is significantly lower in nonevent contacts $(-1.742$ coefficient, $-22.75 \mathrm{t}$-test), the trust-closure association is significantly stronger for nonevent contacts ( 0.616 coefficient, $11.86 \mathrm{t}$-tests), but the low association between closure and trust in event contacts is statistically significant $(0.078$ coefficient, 2.19 t-test). We nevertheless focus on trust independent of closure in the text. Two reasons: First, the trust-closure association for event contacts is dwarfed by the magnitude of the trust difference between event and nonevent contacts, and the stronger trust-closure association for nonevent contacts. Second, trust is independent of closure in the strongest event relations. Such relations in our data are with people valued in founding the business (see Table 6 below). Trust in founding contacts is independent of closure (1.54 t-test, $\mathrm{P} \sim 0.13$ ).

[11] Trust in event contacts regardless of closure could be a characteristic of Chinese entrepreneurs, or it could be a characteristic of how entrepreneurs built their businesses in China during the emergence of a market economy. The table below shows lower trust in event contacts and trust more dependent on closure for entrepreneurs who founded older companies in the sample. Testing for interactions with firm age measured as a deviation from the average age shows that trust in event contacts is independent of closure regardless of firm age $(F(2,699)=0.54$, $\mathrm{P} \sim 0.58)$, but level of trust in event contacts is higher from the founders of newer firms $(2.03$ t-test, $\mathrm{P} \sim 0.04)$. Given the weak variation with age, we conclude that trust in event contacts regardless of closure is a characteristic of the Chinese entrepreneurs regardless of when they founded their business.

\begin{tabular}{lcccc}
\hline \hline Firm Age & $\begin{array}{c}\text { Closure and Trust } \\
\text { for NonEvent } \\
\text { Contacts }\end{array}$ & $\begin{array}{c}\text { Level Adjustment } \\
\text { for Event } \\
\text { Contacts }\end{array}$ & $\begin{array}{c}\text { Slope Adjustment } \\
\text { for Event } \\
\text { Contacts }\end{array}$ & $\begin{array}{c}\text { Adjusted Closure } \\
\text { and Trust for } \\
\text { Event Contacts }\end{array}$ \\
\hline New (after 2000) & 0.713 & 1.919 & -0.689 & 0.024 \\
Old (before 2001) & 0.656 & 1.513 & -0.516 & 0.140 \\
All (Table 4) & 0.694 & 1.742 & -0.616 & 0.078 \\
\hline \hline
\end{tabular}

[12] We were concerned that respondent fatigue might account for 'None of the Above' relations because the item eliciting kind of relations is tiring; a respondent has to make several responses for contacts who have several kinds of relations with the respondent. In testament to the high-quality fieldwork providing the data, our concern turned out to be unfounded: (1) All respondents answered the item for some of their contacts, and no respondent left every contact blank on the item. (2) Respondents who named more contacts from 'None of the Above' are respondents who named more contacts generally, and (3) are respondents who are network brokers in that they have disconnected contacts, which makes sense since network brokers are more likely to find contacts beyond the usual sources. The last two conclusions are supported by a Poisson regression in which number of contacts from 'None of the Above' is predicted by the total number of contacts named and network constraint, the predictor of business success in Table 3 (respective z-score test statistics are 5.66 and -4.56). 
[13] We discuss the means in Table 7 because they are readily interpreted, but we checked our conclusions with a multinomial logit equation predicting the distinctions between rows from other variables in the table. Using 'other event contacts' as the reference category, founding contacts are more likely to be trusted (13.60 z-score), and have less contact with other people in the network $(-8.10 \mathrm{z}$-score for structural embedding). Both of these points are illustrated by the higher, flatter regression line for founding contacts in Figure 4B. Founding contacts are no more likely to be seen frequently than other event contacts $(-.91 \mathrm{z}$-score), but all event contacts are seen more often than nonevent contacts $(-10.75 \mathrm{z}$-score). Founding contacts are known for more years than other event contacts (15.28 z-score), and are the most likely to be members of the entrepreneur's family ( $6.43 \mathrm{z}$-score). The distinction between founders versus other respondents is irrelevant to the contact distinctions ( $-0.55 \mathrm{z}$-score). Test statistics are adjusted down for autocorrelation between relations described by the same respondent ('cluster' option in Stata).

[14] Of 700 entrepreneurs interviewed in the previous survey, 116 were not available for the 2012 survey, and were replaced. The additional businesses drawn for the 2012 survey are independent of the sampling strata: firm size $(1.40$ chi-squared, 2 d.f., $\mathrm{P} \sim 0.50)$, industry (5.28 chi-squared, 4 d.f., $\mathrm{P} \sim 0.26$ ), and city (1.72 chi-squared, 6 d.f., $\mathrm{P} \sim 0.94)$. More, the added respondents are no more or less likely to be founders of their sampled business $(0.08$ chi-squared, 1 d.f., $\mathrm{P} \sim 0.78$ ). Their businesses are no more or less likely to be successful as predicted in the fourth column of Table $1(1.354 \mathrm{t}$-test, $\mathrm{P} \sim 0.18)$, and they are no more or less likely to trust their contacts as predicted in Table $2(0.44 \mathrm{t}$-test, $\mathrm{P} \sim 0.66)$.

\section{APPENDIX: RESEARGH DESIGN}

The design provides data on the strength of relations with, and among, key contacts for each survey respondent in a representative sample of Chinese entrepreneurs.

\section{Population and Sample}

The target population is private businesses in the Yangtze River Delta region, the region from which entrepreneurial activity blossomed in the 1990s for the Chinese economy. The region was distinguished in 1982 by the Chinese national government as the Shanghai Economic Area to provide more local government autonomy for economic development. The initial area included Shanghai, plus four cities in Jiangsu Province (two of which are included in the network survey, Changzhou and Nantong), and five cities in Zhejiang Province (two of which are included in the network survey, Hangzhou and Ningbo). The ten cities expanded over time to include 22 in 2016, members of the Yangtze River Delta Economic Coordination Association. The region is dominated by China's financial center, Shanghai, with Nanjing the capital of Jiangsu Province to the north, and Hangzhou, the capital of Zhejiang Province, to the south.

The survey respondents are a stratified random sample of entrepreneurs founding businesses in the region. As described by Nee and Opper (2012: Chp. 3), the sample is stratified within the seven cities listed in Figure Al by industry (electronics, machinery, pharmaceuticals, textiles, and transportation equipment), and size of company (following China's national classification system of small [10-100 salaried employees], medium [101-300], and large [> 300]). All of the sample firms are entrepreneurial ventures, but $79 \%$ of them are in 2012 mature ventures in the sense that they had survived more than eight years. The means in Figure Al show that the average respondent in 2012 was 45 years old, running a business founded eleven years earlier. Most of the respondents founded the business for which they were sampled (80\%); another $8 \%$ were owners, with the remaining $12 \%$ senior managers of the business. Founders and owners were more likely to be the respondent for small businesses $(91 \%)$, but a substantial $73 \%$ of the respondents for large businesses were also founders and owners. One hundred entrepreneurs were interviewed from each city. The bar charts in Figure A1 show that each city provided entrepreneurs leading small and large companies, with small firms more likely in Nanjing and Changzhou, less likely in Nantong (large shipping port) and Shanghai (financial hub). Wenzhou was not part of the Yangtze River Delta Economic Coordination Association at the time of the initial 2006 survey, nor the 2012 survey including the network module. Wenzhou was 


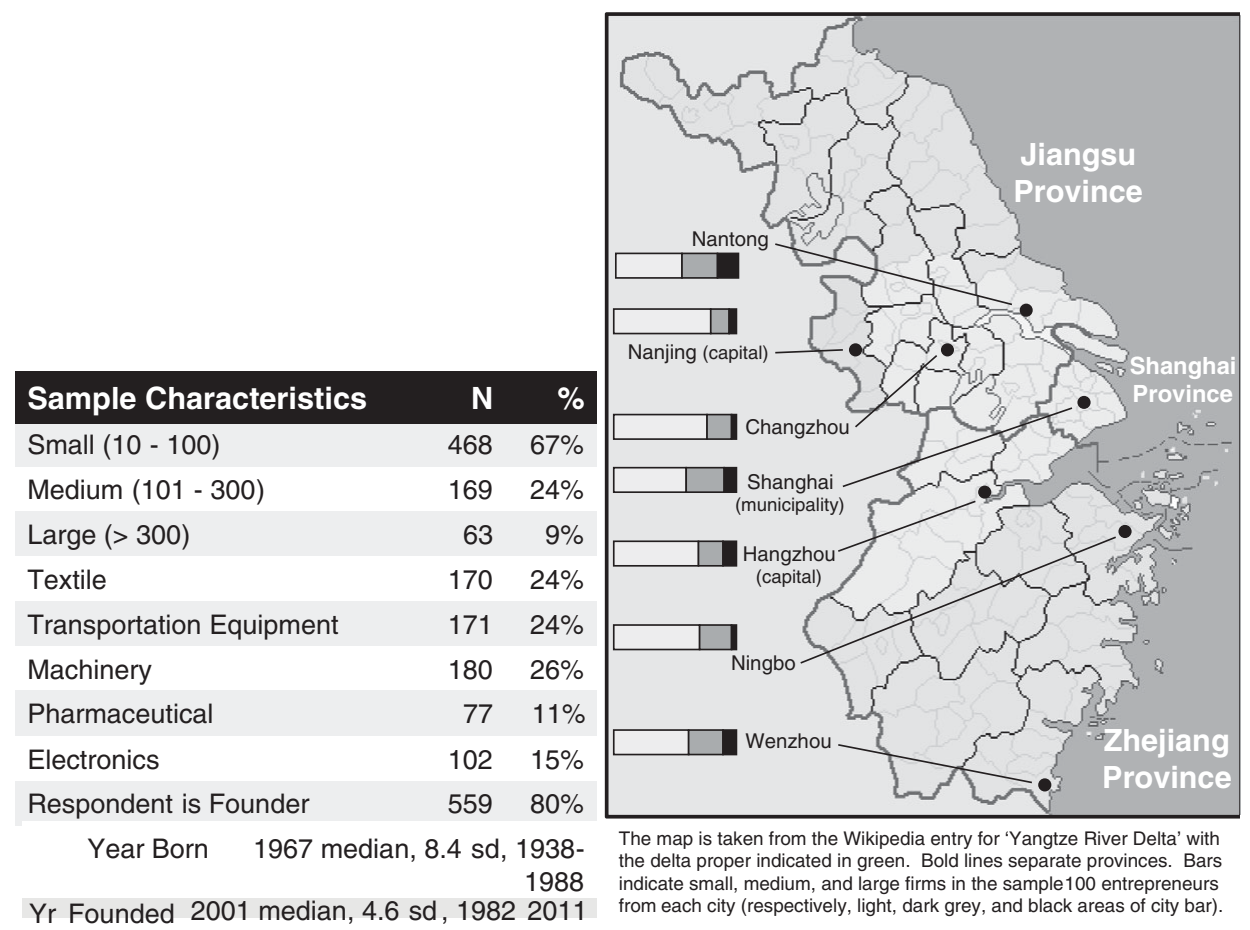

Figure A1. Stratified random aample of 700 Chinese Entrepreneurs from seven cities in three provinces of China's Yangtze River Delta Region.

included in the sampling frame because it is so often mentioned as the 'epicenter', protected by its geographic isolation, from which entrepreneurial practice took hold and spread north to the larger cities (Nee \& Opper, 2012: $41 \mathrm{ff}$.).

As explained by Nee and Opper (2010: Chp. 3), participants were recruited for the initial survey in 2006 using a roster of private companies registered with China's Bureau of Industry. The registry excluded from the population small-scale household companies and fly-by-night businesses illegitimate informal economy firms that have a short life span. Nee and Opper further narrowed the population by excluding companies in business for less than 3 years and small companies (less than 10 salaried workers). To strengthen the focus on viable businesses and capitalist firms, Nee and Opper over-sampled medium (100- 300 employees) and large-scale firms (more than 300 employees). Randomly selected firms were contacted by mail and phone to arrange for interview appointments with their CEOs. To maintain the original sample size, lost respondents were selected for the subsequent two survey waves (2009 and 2012), following the same random sampling procedure described above. ${ }^{[14]}$ The 700 survey respondents do not provide a representative sample of private firms in China given sampling strata defined by affluent cities in a prosperous region, but neither are their stories peculiar. Opper, Nee, and Holm (Forthcoming: 21) summarize as follows the contrast between sample and national: 'Specifically, the sample firms are slightly larger (with an average 130 compared to 117 employees) and more profitable (with a mean annual profit of 3.9 million CNY compared to 3.4 million nationally)'.

There are several advantages to the research design. The high proportion of owners and founders in the sample who have been with the company from the very beginning of its operation provides excellent conditions for the collection of network data also incorporating historical entries covering the earlier life-course of the company. Another important advantage of our sample is the remarkably high re-survey rate accomplished in 2012: 83 percent of the respondents in our 2012 survey also participated in 2009. This provides opportunities to control for earlier economic records to separate 
network effects observed today from mere signaling effects that might occur if today's networkstructure were simply be reflection of past success (breeding today's success). A final advantage of earlier rounds of data is the rich data-base allowing us to check for logical breaks and detection of potentially false entries in the 2012 survey, which could be detected and corrected before the fieldwork ended.

As implied by the previous sentence, the survey fieldwork was carefully controlled to ensure quality data. All data were collected in face-to-face interviews conducted by teams of two professional local interviewers, who typically conducted the interview at the company's premises. The great majority of interviews were conducted in the manager's office, without additional persons present. All interviewers had previously undergone intense multi-day training workshops, received detailed manuals, and instructions that were taken to the field providing quick answers for trouble-shooting and specifying the code-of-conduct during the interview process. Focus groups discussed the survey instrument for accuracy and the feasibility. Before taking the survey to the field, the instrument was subjected to an extended pre-test with a group of 70 entrepreneurs randomly sampled for this purpose from the same cities and industrial sectors as the main survey. The pretests were used to check on the effectiveness of the questionnaire design, as well as ensure the consistent quality of interviews and interviewers. These precautions resulted in two significant changes to the initial network module, one to protect network confidentiality, and a second to define trust in a way meaningful to the respondents.

\section{Name Generator Items}

The six name generator questions are listed in Table Al, in the order in which questions were asked in the interview. The survey instrument and materials used with the entrepreneurs are available to download in the original English (see acknowledgement note). Questions 3, 4, and 5 are generic questions in management research describing a business leader's current network. Question 3 asks for the names of people who the respondent feels are most valuable in his or her business activities. Question 4 is included to ensure that difficult people are included in the network inventory, and question 5 is to ensure that externally focused entrepreneurs include at least one valuable employee in the business.

\section{Event Name Generator Items}

To stretch the network data back into the history of a respondent's business, event name generators were used. The idea is to create a time line of concrete events back in time, then ask for the names of contacts who were especially valuable to the respondent during the event. The item is illustrated in Figure A2. The interviewer guides the respondent through the example at the top of Figure A2 as the respondent completes the time line below for his or her business. The year of the survey is to the right, 2012. To the left, the respondent enters the year his or her business was founded, marks the mid-point between the dates, and the midpoints at the quarter periods. The respondent is then asked to indicate the year and nature of significant events in the business. Here are the instructions to the respondent after the four dates had been written on the time line:

Use the four dates as a frame of reference to write in each year during which you experienced a significant event for your business. Please limit yourself to five or fewer significant events. We rely on your judgment to determine what events are significant, but examples could include events like the ones that happened to the example firm at the top of your worksheet. After the firm was founded in 1992, the owner secured a relationship with a key technology partner in 1993. The business prospered. To expand faster, a bank loan was obtained in 1999. In 2000, the firm had to deal with the problem that a critical supplier was purchased so it was no longer available. A new supplier was arranged and the business grew into its first export contract in 2004. Four years later, in 2008, a contract was secured with the current primary export customer.

Different firms have different histories. In the space at the bottom of your worksheet, please indicate up to five significant events in the history of your firm. Please be sure to include the year in which each event took place. You have a lot of space; so don't worry about scratching things out. 
Table Al. Relations elicited from the Chinese entrepreneurs

\begin{tabular}{|c|c|c|c|c|c|}
\hline Survey Name Generator (as ordered in interview) & $\begin{array}{c}\text { Total } \\
\text { Number } \\
\text { Contacts }\end{array}$ & $\begin{array}{l}\text { Mean } \\
\text { Number } \\
\text { Contacts }\end{array}$ & $\begin{array}{l}\text { Standard } \\
\text { Deviation }\end{array}$ & Min & $\operatorname{Max}$ \\
\hline $\begin{array}{l}\text { 1. (FOUNDING) Who was the one person who } \\
\text { was most valuable to you in founding the firm? }\end{array}$ & 700 & 1.00 & 0.00 & 1 & 1 \\
\hline $\begin{array}{l}\text { 2. (OTHER EVENTS) Now please do the same } \\
\text { thing for each of the significant events you } \\
\text { listed. The first significant event you listed was } \\
\text { (say first event) in (say year). Who was the } \\
\text { person most valuable to you during that event? }\end{array}$ & 2,701 & 3.86 & 0.90 & 1 & 5 \\
\hline $\begin{array}{l}\text { 3. (CURRENT) Shifting now to business this } \\
\text { year, and thinking about people inside or } \\
\text { outside your firm, who are the three or four } \\
\text { people who have been most valuable to your } \\
\text { business activities this year? }\end{array}$ & 2,357 & 3.37 & 0.50 & 2 & 4 \\
\hline $\begin{array}{l}\text { 4. (DIFFICULT) In contrast to people who help } \\
\text { and are valued in your business activities, there } \\
\text { are usually some people who make life difficult. } \\
\text { Without mentioning the person's name, who } \\
\text { was the most difficult person to deal with in } \\
\text { your business activities this year? Just jot a } \\
\text { name or initials in the box below. Only you are } \\
\text { going to know who this person is. }\end{array}$ & 700 & 1.00 & 0.00 & 1 & 1 \\
\hline $\begin{array}{l}\text { 5. (EMPLOYEE) Shifting to happier thoughts, } \\
\text { who do you think was your most valuable } \\
\text { senior employee this year? }\end{array}$ & 700 & 1.00 & 0.00 & 1 & 1 \\
\hline $\begin{array}{l}\text { 6. (NEC) Now that you have a list of contacts on } \\
\text { the roster worksheet, please look it over quickly. } \\
\text { Is there anyone particularly significant for your } \\
\text { business who has not been mentioned? If yes, } \\
\text { please enter their name at the bottom of the list. } \\
\text { There are many people you could mention. } \\
\text { These would just be people particularly } \\
\text { significant for your business. The roster can } \\
\text { hold a maximum of } 14 \text { names. }\end{array}$ & 16 & 0.02 & 0.23 & 0 & 4 \\
\hline TOTAL & 4,464 & 6.38 & 1.48 & 3 & 12 \\
\hline
\end{tabular}

Notes: First column is the total number of contacts cited by all 700 respondents on the row name generator, then the mean and standard deviation of the number cited by individual respondents, then the minimum and maximum number cited by individual respondents.

Upon finishing the time line, the respondent was asked the first name generator in Table Al: 'Who was the one person most valuable to you in founding the firm'? A similar question was posed for each of the significant events listed. Table Al shows that all 700 respondents named a contact most valuable when the firm was founded, then named an average of 3.86 contacts most valuable during subsequent events. For each of these 'event' contacts, we know the event year and the kind of event in which the respondent valued the contact. Of course, the same person could be named on multiple events and multiple name generators.

The final name generator in Table Al is a 'not elsewhere classified' generator used to ensure that a critical contact had not yet been missed. Only 16 respondents had another name to add to the ones already listed. In total, respondents named an average of 6.38 contacts, varying from a minimum of three up to a maximum of 12 . 


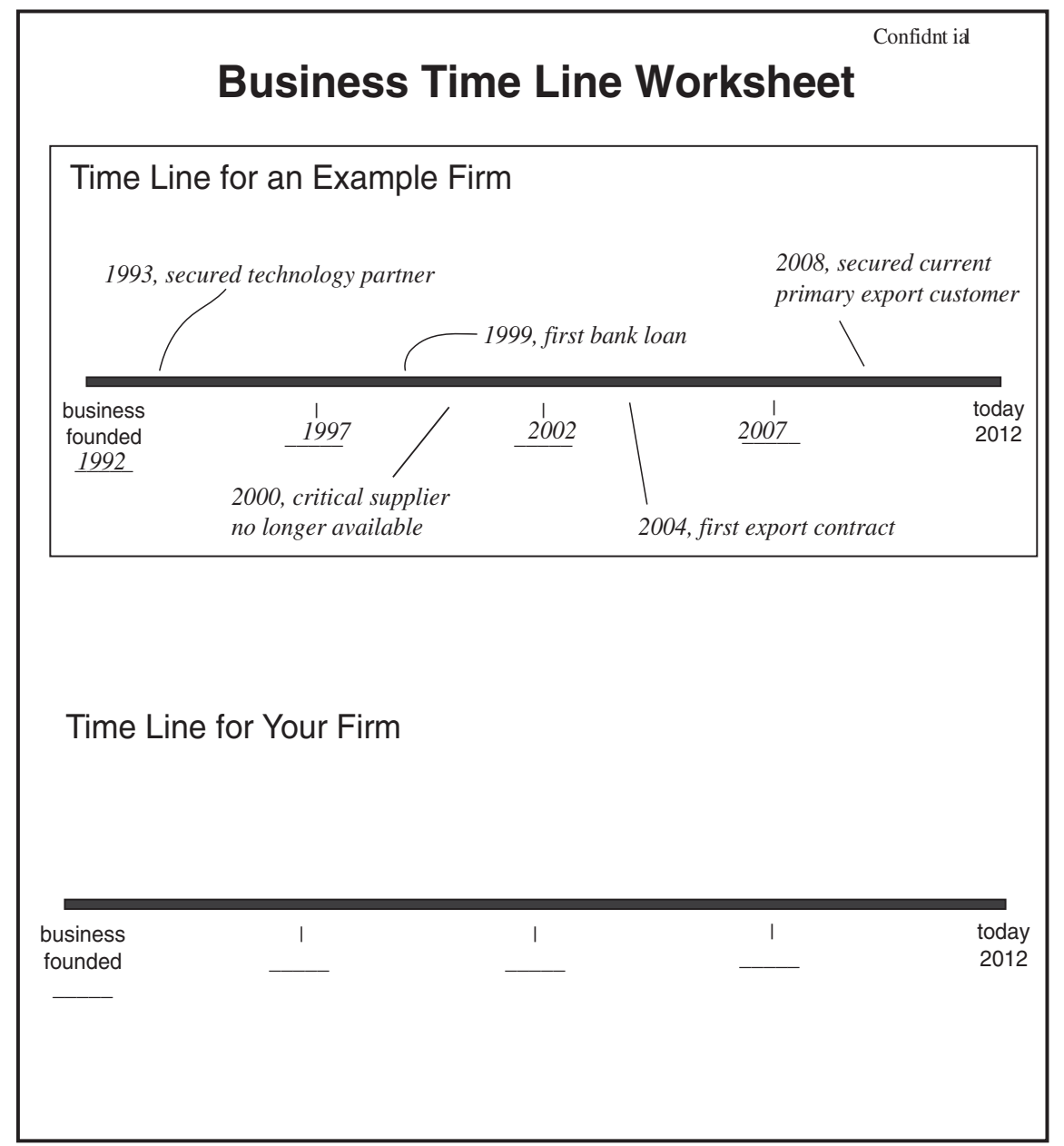

The next five questions generate a summary picture of the business network. To draw the picture, you will be asked about people, but we do not want to know any one's name. I will go through this network worksheet with you, asking about people who were useful to your business in one way or another. Without mentioning anyone's name to me, please write on your worksheet the names of people who come to mind in response to the questions. We will create a list of names then refer to people by their order on the list. No names. You will keep the worksheet to yourself.

Q1. Let me begin with an example so you can see how the interview protects your confidentiality at the same time that a picture of the business network emerges. Your business time line shows that your firm was founded in _(say founding year)_. Please think back to your activities in founding the firm. Who was the one person who was most valuable to you in founding the firm?

Q2. Now please do the same thing for each of the significant events you listed on your business time line. The first significant event you listed was _ _(say first event)__ in _(say year)_. Who was the person most valuable to you during that event? Please write on the first line below the person's name. The person most valuable in this event could be the same person who was most valuable to you in founding the firm. You would just enter the name again.

Figure A2. Business event name generator

\section{Name Interpreter Items}

Given a roster of key contacts, the name interpreters in Figure A3 were used to elicit data on contact gender, the substance of the respondent's connection with each contact (emotional closeness, duration, frequency, trust), the variety of roles in which respondent and contact have been linked (family, neighbor, party, childhood, classmate, military, co-worker, co-member business association), and the strength of connections between contacts. With specific relevance to scaling relations, respondents were asked whether their relationship with each contact was 'especially close', 'close', 
- Contact Gender (male, female)

- Emotional Closeness to Contact (especially close, close, less close, distant)

- Duration of Connection with Contact (years known)

- Frequency of Contact (daily, weekly, monthly, less often)

- Trust (1 to 5, low to high trust) "Consider the extent to which you trust each of the listed people. For example, suppose one of the people asked for your help. The help is not extreme, but it is substantial. It is a level of help you cannot offer to many people. To what extent would you trust each person to give you all the information you need to decide on the help? For example, if the person was asking for a loan, would they fully inform you about the risks of them being able to repay the loan? If the person was asking you give a job to one of their relatives, would they fully inform you about their relative's poor work attitude or weak abilities, or other qualities that would make you prefer not to hire the relative?"

- Role (all that apply: family, extended family, neighbor, party, childhood, classmate, military, colleague, business association)

- Matrix of Connections between Contacts (especially close, distant, or something in between)

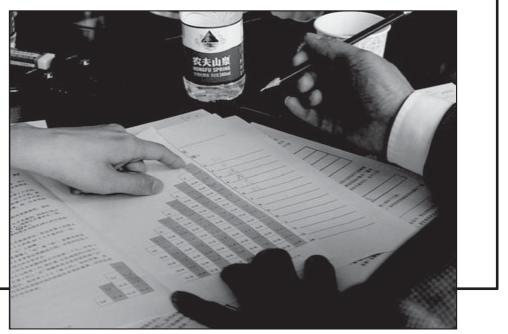

Figure A3. Name Interpreters Flesh Out Relationships and Define Connections among Cited Contacts

'less close', or 'distant'. They were also asked to describe whether the connection between each person named was 'especially close', 'distant', or something in between ('neither distant nor especially close').

The items listed in Figure A3 are generic to survey network data, with the exception of the trust item. Two versions of the trust item were pre-tested, the one in Figure A3 based on full disclosure, and an alternative based on reciprocity: 'For example, suppose one of the listed people asked for your help. The help is not extreme, but it is substantial. It is a level of help you cannot offer to many people. To what extent would you trust each person to do the right thing in returning a comparable favor in the future, either by helping you is a similarly significant way, or providing suitable compensation for your help'? Respondents in the pre-test had no difficulty with the idea of reciprocity, but the 'right thing' to do varied across respondents and kinds of contacts. The full disclosure version in Figure A3 had consistent meaning for the respondents, so it became the version used in the survey.

The usual name generator/interpreter format was modified slightly to ensure respondent comfort talking about network contacts. First, as was learned with the network items in the General Social Survey, respondents often stopped at three names in response to multi-name questions, so interviewers prompted with 'Anybody else'? Second, the pre-test revealed discomfort in naming contacts, even though the respondents were encouraged to use nicknames and it would have been prohibitively expensive to track down a contact with the limited information elicited. The discomfort could have been something about the way the name generators were asked because Batjargal et al. (2013:1034n) found it sufficient to limit contacts to surnames for name generators posed in telephone interviews with Chinese entrepreneurs in Beijing, as did Zhang and Wong (2008:418), who relied on surnames because they found: it is difficult to find businessman willing to talk openly about their network utilization. In particular, in recent years, using personal ties for venture fundraising from government agency or banks may be considered improper behavior'. Whatever the reason, comfort was secured in this study by using worksheets. Assisted by the interviewer, the respondent wrote his or her responses in the interview booklet using his or her own words. For the name generators, however, the respondent wrote contact names on a worksheet separate from the booklet. When the name generator items were complete, a sequential, non-redundant roster of contact names was created on a second worksheet for reference when answering the subsequent name interpreter items. The respondent kept both work- 
sheets in his or her possession after the interview. When the roster was complete, the interviewer used it to transcribe to the interview booklet, from the respondent's worksheet, the sequential ID number of contacts named for each name generator. In the interview booklet sent to data entry, contacts were referenced only by ID number. The interviewer took away no names of contacts cited in the interview. The network data are complete on almost every respondent, a commendable achievement considering the nature and complexity of the questions, and the business leaders being interviewed.

\section{Scaling the Data}

It is not uncommon to see categorical network data scaled in an ad hoc way to compute network metrics. Relations can be dichotomized into present versus absent (strong response category is a 1 , else 0 ), or assigned a level of strength from the number of response categories (e.g., 1 for 'especially close' in the Chinese network module, .75 for 'close', .50 for 'less close', and .25 for 'distant').

An alternative is to infer relation strength from the way respondents use response categories. The general idea, based on balance theory (Doreian, Kapuscinski, Krackhardt, \& Szczypula, 1996; Heider, 1958), is that the respondent's relationship with a contact should be proportional in strength to the strength of relations that respondent and contact have with other contacts. If I feel close to Jie, I expect the other people close to me to feel close to Jie. The people from whom I feel distant I expect to feel distant from Jie. For probability samples of disconnected networks, such as the General Social Survey, Burt and Guillarte (1986) proposed that an 'anchor' contact be identified as the contact most strongly connected to the respondent. By balance theory, the strength of the respondent's relationship with his anchor contact should be proportional to the strength of his perceived relationship between anchor and each other contact named. Associations between categories of relationship can be used to scale the categories relative to one another.

Figure A4 shows the results for the Chinese entrepreneurs (cf. Burt, 2010: 290-292, for similar results within a management population). The anchor contact for each respondent is a person with whom the respondent has the strongest direct and indirect connection. Rows in the Figure A4 table distinguish categories of relation strength between respondents and their anchor contact. The 700 respondents cited a total of 4,464 contacts of whom one per respondent is an anchor contact. The other cited contacts are distributed across the columns in the Figure A4 table according to their connection with the respondent's anchor contact. The graphic in Figure A4 shows the results of fitting a one-dimensional loglinear association model to the frequencies in the table (Goodman, 1981). There are three broad levels of connection: At the top of the scale, 'especially close' relations are strong, whether they are respondent to contact, or contact to contact. In the middle are 'close', 'less close', and something 'neither distant nor especially close'. 'Distant' relations are together at the bottom of the scale. When scaled to vary from zero to one, the scores in Figure A4 define the following category scores: especially close (1.0 with contacts, 0.99 between contacts), close $(0.57)$, neither close nor distant between contacts (0.44), less close (0.29), and distant $(0.06$ with contacts, 0.00 between contacts). From left to right in Figure A4, the loglinear scores are $-0.677,-0.599$, $-0.270,-0.058,0.127,0.734$, and 0.743 . Scaled category scores are computed as a loglinear score plus 0.677 , quantity divided by $(0.743+0.677)$.

The final result is a symmetric, square matrix of variables measuring the strength of connections between respondent and his or her cited contacts, and between each pair of cited contacts. Table A2 contains descriptive statistics on network indices computed from the matrix for each respondent. The listed indices are often used to measure the advantage provided by a network: size, structural embedding, density, constraint, effective size, and betweenness. These measures are widely available in network analysis software packages (Burt, 2010: 293-300; 2015). The 0.47 mean density and 0.57 mean network constraint for the Chinese entrepreneurs are close to the respective means of 0.42 and 0.51 reported by Batjargal et al. (2013: 1036) for sample entrepreneurs in China, France, Russia, and the United States.

There are no network data on Western entrepreneurs comparable to what we have on the Chinese entrepreneurs, so we include in Table A2 mean network scores for managers in two American firms as a frame of reference. Firm A is 455 managers in the supply-chain organization of a large American electronics firm (Burt, 2004, 2010). Firm B is 257 sales, service and operations managers 


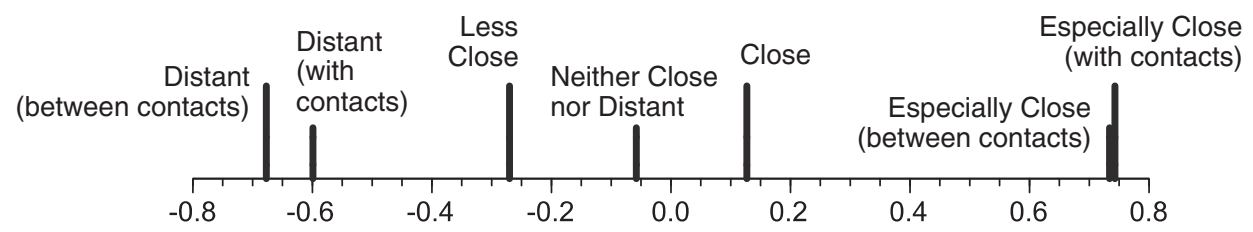

Loglinear Association Model Score

\begin{tabular}{cccc}
\hline $\begin{array}{c}\text { Respondent } \\
\text { Relation with } \\
\text { Contact }\end{array}$ & Especially Close & Middling & Distant \\
\hline Especially Close & 690 & 146 & 86 \\
Close & 1294 & 260 & 462 \\
Less Close & 209 & 95 & 219 \\
Distant & 37 & 39 & 226 \\
\hline
\end{tabular}

NOTE - Rows distinguish relations between the respondent and contacts.

Columns distinguish relations between each contact and the respondent's

"anchor" contact, which is the contact most strongly connected to the respondent. Scores in the graphic come from the first dimension of a loglinear association model fit to the table.

Figure A4. Scaling the Network Data

Note: Rows distinguish relations between the respondent and contacts. Columns distinguish relations between each contact and the respondent's 'anchor' contact, which is the contact most strongly connected to the respondent. Scores in the graphic come from the first dimension of a loglinear association model fit to the table.

Table A2. Descriptive statistics on network metrics computed from the scaled network data

\begin{tabular}{|c|c|c|c|c|c|c|}
\hline & \multicolumn{3}{|c|}{ Managers in Two American Firms } & \multicolumn{3}{|c|}{ Chinese Entrepreneurs } \\
\hline & Firm $A$ & Firm $B$ & Mean & $\begin{array}{l}\text { Standard } \\
\text { Deviation }\end{array}$ & Min & Max \\
\hline $\begin{array}{l}\text { Network Size } \\
\text { (number of cited contacts) }\end{array}$ & 9.09 & 7.07 & 6.38 & 1.48 & 3 & 12 \\
\hline $\begin{array}{l}\text { Structural Embedding } \\
\text { (mean number of contacts connected } \\
\text { to respondent's contacts) }\end{array}$ & 3.55 & 3.31 & 2.97 & 1.16 & 0.00 & 8.33 \\
\hline $\begin{array}{l}\text { Network Density } \\
\text { (mean connection strength between } \\
\text { contacts) }\end{array}$ & 0.43 & 0.49 & 0.47 & 0.18 & 0.00 & 1.00 \\
\hline $\begin{array}{l}\text { Effective Size } \\
\text { (network size adjusted down for } \\
\text { redundant contacts) }\end{array}$ & 6.52 & 4.35 & 3.66 & 1.44 & 1.00 & 8.17 \\
\hline $\begin{array}{l}\text { Network Constraint } \\
\text { (zero to one, lack of structural holes } \\
\text { among contacts) }\end{array}$ & 0.42 & 0.49 & 0.57 & 0.14 & 0.20 & 1.00 \\
\hline $\begin{array}{l}\text { Network Betweenness } \\
\text { (zero to one, monopoly access to } \\
\text { structural holes between contacts) }\end{array}$ & 0.46 & 0.37 & 0.37 & 0.19 & 0.05 & 1.00 \\
\hline
\end{tabular}


involved in the Asia-Pacific launch of a new product from a large American software company (Burt, 2010). The managers completed network surveys, but with name generator and interpreter items more limited than the items to which the Chinese entrepreneurs responded. The American data are merely provided as a frame of reference. Our sense is that the Chinese networks are not wildly different from the American networks. The Chinese networks are smaller and more dense than the networks in either American firm, but relatively similar to networks around the Asia-Pacific managers in the software company (average across rows of absolute difference in American and Chinese means divided by Chinese mean).

\section{REFERENCES}

Allen, T.J., \& Cohen, S. I. 1969. Information flow in research and development laboratories. Administrative Science Quarterly, 14(1): 12-19.

Asch, S. E. 1951. Effects of group pressure upon the modification and distortion of judgments. In H. Guetzkow (Ed.), Groups, leadership and men: 177-190. Pittsburgh, PA: Carnegie Press.

Barker, J. R. 1993. Tightening the iron cage: Concertive control in self-managing teams. Administrative Science Quarterly, 38(3): 408-437.

Batjargal, B. 2007a. Comparative social capital: Networks of entrepreneurs and venture capitalists in China and Russia. Management and Organization Revieze, 3(3): 397-419.

Batjargal, B. 2007b. Internet entrepreneurship: Social capital, human capital, and performance of internet ventures in China. Research Policy, 36(5): 605-618.

Batjargal, B. 2010a. Network dynamics and new ventures in China: A longitudinal study. Entrepreneurship \& Regional Development, 22(2): 139-153.

Batjargal, B. 2010b. The effects of network's structural holes: Polycentric institutions, product portfolio, and new venture growth in China and Russia. Strategic Entrepreneurship Journal, 4(2): 146-163.

Batjargal, B., Hitt, M. A., Tsui, A. S., Arregle, J.-L., Webb, J. W., \& Miller, T. L. 2013. Institutional polycentrism, entrepreneur's social networks, and new venture growth. Academy of Management Journal, 56(4): 1024-1049.

Bernstein, L. 1992. Opting out of the legal system: Extralegal contractual relations in the diamond industry. Journal of Legal Studies, 21(1): 115-157.

Bernstein, L. 2001. Private commercial law in the cotton industry: Creating cooperation through rules, norms, and institutions. Michigan Laze Revieze, 99(7): 1724-1790.

Bian, Y. 1997. Bringing strong ties back in: Indirect ties, network bridges, and job searches in China. American Sociological Revieze, 62(3): 366-385.

Bian, Y. Forthcoming. The prevalence and increasing significance of guanxi. In K. Latham (Ed.), The Routledge handbook of Chinese culture and society. London: Routledge.

Bian, Y., \& Li, L. 2012. The Chinese General Social Survey (2003-8). Chinese Sociological Revieze, 45(1): 70-97.

Bian, Y., \& Wang, W. 2016. The social capital for self-employment in transitional China. In J.H. Wang \& R.-M. Hsung (Eds.), Rethinking social capital and entrepreneurship in greater China: 21-35. New York: Routledge.

Bian, Y., \& Zhang, L. 2014. Corporate social capital in Chinese guanxi culture. Research in the Sociology of Organizations, 40: 421-443.

Borgatti, S. P. 2002. NetDraze. Boston, MA: Analytic Technologies.

Burt, R. S. 1982. Tozeard a structural theory of action. New York: Academic Press.

Burt, R. S. 1984. Network items and the General Social Survey. Social Networks, 6(4): 293-339.

Burt, R. S. 1987. A note on the General Social Survey's ersatz network density item. Social Networks, 9(1): 75-85.

Burt, R. S. 1992. Structural holes. Boston, MA: Harvard University Press.

Burt, R. S. 1998. The gender of social capital. Rationality and Society, 10(1): 5-46.

Burt, R. S. 2004. Structural holes and good ideas. American Journal of Sociology, 110(2): 349 399.

Burt, R. S. 2005. Brokerage and closure. Oxford: Oxford University Press.

Burt, R. S. 2010. Neighbor networks. New York: Oxford University Press.

Burt, R. S. 2015. Reinforced structural holes. Social Networks, 43: 149-161.

Burt, R. S. \& Guilarte, M. G. 1986. A note on scaling the General Social Survey network item response categories. Social Networks, 8: 387-396. 
Burt, R. S., Kilduff, M., \& Tasselli, S. 2013. Social network analysis: Foundations and frontiers on network advantage. Annual Revieze of Psychology, 64: 537-547.

Burt, R. S., \& Merluzzi, J. 2016. Network oscillation. Academy of Management Discoveries, 2 : 368-391.

Chen, C. C., Chen, X.-P., \& Huang, S. 2013. Chinese guanxi: An integrative review and new directions for future research. Management and Organization Revieze, 9(1): $167-207$.

Chen, X.-P., \& Chen, C. C. 2004. On the intricacies of the Chinese guanxi: A process model of guanxi development. Asia Pacific Journal of Management, 21(3): 305324.

Coleman, J. S. 1988. Social capital in the creation of human capital. American Journal of Sociology, 94: S95-S120.

Cook, K. S., Emerson, R. M., Gillmore, M. R., \& Yamagishi, T. 1983. The distribution of power in exchange networks: Theory and experimental results. American Journal of Sociology, 89(2): 275-305

Doreian, P., Kapuscinski, R., Krackhardt, D., \& Szczypula, J. 1996. The history of balance through time. Journal of Mathematical Sociology, 21(1-2): 113-131.

Festinger, L., Schachter, S., \& Back, K. W. 1950. Social pressures in informal groups. Stanford, CA: Stanford University Press.

Fischer, G. S. 1982. To dwell among friends. Chicago, IL: University of Chicago Press.

Freeman, L. C. 1977. A set of measures of centrality based on betweenness. Sociometry, 40(1): $35-40$.

Goldberg, A., Srivastava, S. B., Manian, V. G., Monroe, W., \& Potts, C. 2016. Fitting in or standing out? The tradeoffs of structural and cultural embeddedness. American Sociological Revieze, 81(6): 1-33.

Goodman, L. A. 1981. Association models and canonical correlation in the analysis of crossclassifications having ordered categories.Journal of the American Statistical Association, 76(374): 320-334.

Granovetter, M. 1973. The strength of weak ties. American Journal of Sociology, 78(6): 13601380.

Granovetter, M. 1985. Economic action, social structure, and embeddedness. American Journal of Sociology, 91(3): 481-510.

Granovetter, M. 1992. Problems of explanation in economic sociology. In N. Nohria \& R. G. Eccles (Eds.), Networks and Organizations: 29-56. Boston, MA: Harvard Business School Press.

Greif, A. 1989. Reputation and coalitions in medieval trade: Evidence on the Maghribi traders. Journal of Economic History, 49(4): 857-882.

Guo, C., \& Miller, J. K. 2010. Guanxi dynamics and entrepreneurial firm creation and development in China. Management and Organization Revieze, 6(2): 267-291.

Heider, F. 1958. The psychology of interpersonal relations. New York: John Wiley.

Hwang, W.-K. 1987. Face and power: The Chinese power game. American Journal of Sociology, 92(4): $944-974$.

Ingram, P., \& Morris, M. W. 2007. Do people mix at mixers? Structure, homophily, and the 'life of the party'. Administrative Science Quarterly, 52(4): 558-585.

Kleinbaum, A. M., \& Stuart, T. E. 2014. Inside the black box of the corporate staff: Social networks and the implementation of corporate strategy. Strategic Management Journal, 35(1): 24 47.

Leavitt, H. J. 1951. Some effects of certain communication patterns on group performance.Journal of Abnormal and Social Psychology, 46(1): 38-50.

Lee, N. H. 1969. The search for an abortionist. Chicago, IL: University of Chicago Press.

Levin, D. Z., Walter, J., \& Murnighan, J. K. 2011. Dormant ties: The value of reconnecting. Organization Science, 22(4): 923-939.

Lin, N. 2001. Social capital. Cambridge, MA: Cambridge University Press.

Lin, N., Ensel, W., \& Vaughn, J. 1981. Social resources and strength of ties: Structural factors in occupational status attainment. American Sociological Revieze, 46(4): 393405.

Lin, N., \& Erickson, B. H. 2008. Social capital. New York: Oxford University Press.

Luo, J.-D. 2011. Guanxi revisited: An exploratory study of familiar ties in a Chinese workplace. Management and Organization Revieze, 7(2): 329-351. 
Luo, J.-D. 2016. The guanxi circle phenomenon in the Chinese venture capital industry. In J.-H. Wang \& R.-W. Hsung (Eds.). Rethinking social capital and entrepreneurship in greater China: 56-71. New York: Routledge.

Luo, J.-D., \& Cheng, M.-Y. 2015. Guanxi circles' effect on organizational trust: Bringing power and vertical social exchanges into intraorganizational network analysis. American Behavioral Scientist, 59(8): 1024-1037.

Luo, J.-D., Cheng, M.-Y., \& Zhang, T. 2016. Guanxi circle and organizational citizenship behavior: Context of a Chinese workplace. Asia Pacific Journal of Management, 33(3): 649671.

Luo, Y., Huang, Y., \& Wang, S. L. 2011. Guanxi and organizational performance: A meta-analysis. Management and Organization Review, 8(1): 139-172.

Ma, R., Huang, Y.-C., \& Shenkar, O. 2011. Social networks and opportunity recognition: A cultural comparison between Taiwan and the United States. Strategic Management Journal, 32(11): 1183-1205.

Marsden, P. V. 1987. Core discussion networks of Americans. American Sociological Review, 52(1): 122-131.

Marsden, P. V. 2011 . Survey methods for network data. In J. P. Scott \& P. J. Carrington (Eds.), The SAGE handbook of social network analysis: $370-388$. Thousand Oaks, CA: Sage.

Merluzzi, J. 2013. Social capital in Asia: Investigating returns to brokerage in collectivistic national cultures. Social Science Research, 42(3): 882-892.

Moreno, J. L. 1947. Organization of the social atom. Sociometry, 10(3): 287-293.

Morris, M. W., Podolny, J. M., \& Ariel, S. 2000. Missing relations: Incorporating relational constructs into models of culture. In C. P. Earley \& H. Singh (Eds.), Innovations in international and cross-cultural management: 52-90. Thousand Oaks, CA: Sage Publications.

Nee, V., \& Opper, S. 2012. Capitalism from below: Markets and institutional change in China. Cambridge, MA: Harvard University Press.

Opper, S., Nee, V., \& Holm, H. J. Forthcoming. Risk aversion and guanxi activities: A behavioral analysis of CEOs in China. Academy of Management Journal, 60: In Press.

Peng, M. W., \& Luo, Y. 2000. Managerial ties and firm performance in a transition economy: The nature of a micro-macro link. Academy of Management Journal, 43(3): 486-501.

Quintane, E., \& Carnabuci, G. 2017. How do brokers broker: Tertius gaudens, tertius ingens, and the temporality of structural holes. Organization Science, 28: In Press.

Ruan, D. 1998. The content of the General Social Survey discussion networks: An exploration of General Social Survey discussion name generator in a Chinese context. Social Networks, 20(3): 247-264.

Tortoriello, M., \& Krackhardt, D. 2010. Activating cross-boundary knowledge: The role of Simmelian ties in the generation of innovations. Academy of Management Journal, 53(1): $167-181$.

Useem, M. 1984. The inner circle. New York: Oxford University Press.

Uzzi, B. 1997. Social structure and competition in interfirm networks: The paradox of embeddedness. Administrative Science Quarterly, 42(1): 35-67.

Vissa, B., \& Chacar, A. S. 2009. Leveraging ties: The external value of entrepreneurial teams' external advice networks on Indian software venture performance. Strategic Management Journal, 30(11): 1179-1191.

Wasserman, N. 2012. The founder's dilemmas. Princeton, NJ: Princeton University Press.

Xiao, Z., \& Tsui, A. S. 2007. When brokers may not work: The cultural contingency of social capital in Chinese high-tech firms. Administrative Science Quarterly, 52(1): 1-31.

Yang, J., \& Zhang, J. 2015. Social networks, cognition and risk recognition in new ventures: Evidence from China. Journal of Developmental Entrepreneurship, 20(2): 1550012-1-27.

Zhang, J., \& Wong, P.-K. 2008. Network vs. market methods in high-tech venture fundraising: The impact of institutional environment. Entrepreneurship and Regional Development, 20: 409-430. 
Ronald S. Burt (ron.burt@chicagobooth.edu) is the Hobart W. Williams Professor of Sociology and Strategy at the University of Chicago Booth School of Business. He received his $\mathrm{PhD}$ in Sociology from the University of Chicago. His work describes how social networks create competitive advantage.

Katarzyna Burzynska (K.Burzynska@fm.ru.nl) is an Assistant Professor, Department of Economics, Radboud University Nijmegen. She received her $\mathrm{PhD}$ in Economics from Lund University. Her work concerns financial and institutional economics, network analysis, and China's economy.

Manuscript received: December 8, 2016

Final version accepted: January 23, 2017

Accepted by: $\quad$ Editor-in-Chief Arie Y. Lewin 